\title{
A Soil Bioassay for Predicting the Risk of Spinach Fusarium wilt
}

\author{
Emily W. Gatch and Lindsey J. du Toit, Washington State University Mount Vernon Northwestern Washington Research \& Extension
} Center, Mount Vernon 98273-4768.

\begin{abstract}
Gatch, E. W., and du Toit, L. J. 2015. A soil bioassay for predicting the risk of spinach Fusarium wilt risk. Plant Dis. 99:512-526.

The maritime Pacific Northwest is the only region of the United States suitable for production of spinach seed, a cool-season, daylengthsensitive crop. However, the acidic soils of this region are highly conducive to spinach Fusarium wilt, caused by Fusarium oxysporum f. sp. spinaciae. Rotations of at least 10 to 15 years between spinach seed crops are necessary to reduce the high risk of losses to this disease. The objectives of this study were to develop a greenhouse soil bioassay to assess the relative risk of Fusarium wilt in fields intended for spinach seed production, and to identify soil chemical and physical properties associated with conduciveness to this disease. Preliminary bioassays established a protocol for growing spinach plants in a greenhouse environment and inducing Fusarium wilt symptoms so that the bioassay can be completed in $<2$ months. Test soils with a range of Fusarium wilt inoculum potentials, and three spinach inbred parent lines (highly susceptible, moderately susceptible, and moderately resistant to Fusarium wilt) were used to evaluate sensitivity of the bioassay to different levels of risk of Fusarium wilt. Then, from 2010 to 2013, spinach seed growers and stakeholders submitted soil samples from 147 fields for evaluation with the

bioassay. The fields were each under consideration for planting a spinach seed crop, yet the bioassay revealed a wide range in Fusarium wilt inoculum potential among soil samples. Differences in susceptibility to Fusarium wilt of the three inbred lines were key to detecting differences in wilt risk among soils. Visits to spinach seed crops planted in fields evaluated in the bioassay, as well as test plots of the three inbred lines planted in growers' seed crops, confirmed the predictive value of the bioassay for Fusarium wilt risk. Correlation analyses for 23 soil properties revealed significant relationships of 15 soil properties with the Fusarium wilt potential of a soil, but the correlations were influenced significantly by susceptibility of the inbred line to Fusarium wilt $(13,10$, and 8 soil properties correlated significantly with Fusarium wilt risk for the susceptible, moderate, and partially resistant inbreds, respectively). Multiple regression analyses identified different statistical models for prediction of Fusarium wilt risk depending on the spinach inbred line, but the best fitting model explained $<34 \%$ of the variability in Fusarium wilt risk among 121 fields evaluated in the soil bioassay. Thus, no model was robust enough to replace the bioassay for the purpose of predicting Fusarium wilt risk.
\end{abstract}

Production of high quality spinach (Spinacia oleracea L.) seed requires a mild climate, long summer daylength to trigger uniform bolting (conversion from vegetative to reproductive growth), and dry weather conditions during seed set and maturation (33). The maritime Pacific Northwest (PNW) region of the United States (western Oregon and western Washington) is one of the few regions in the world that meets these requirements, and is the source of up to $50 \%$ of the spinach seed supply for the United States and up to $20 \%$ of the global spinach seed supply (14). However, the leached, acid soils of the PNW are highly conducive to spinach Fusarium wilt caused by Fusarium oxysporum f. sp. spinaciae (14). This disease causes wilting and chlorosis of leaves, plant stunting, internal vascular discoloration and necrosis of roots, premature senescence, and severely reduced seed yields $(9,10-12)$. The pathogen can persist as chlamydospores in soils for extended periods, forcing growers to wait 15 years or more between spinach seed crops to avoid major losses (14). Partial resistance to the disease has been identified, but many of the commonly used parent lines for seed production have little or no resistance (9). Furthermore, growers contract with seed companies to produce hybrid spinach seed (14) and typically have no choice or knowledge of the relative resistance to Fusarium wilt of the proprietary spinach lines they are contracted to grow. Sufficient pollen isolation distances must also be maintained among seed crops of this wind-pollinated, dioecious species to ensure genetic purity of the harvested seed. This further complicates the placement of spinach seed crops in suitable fields.

The most effective way to reduce losses to spinach Fusarium wilt in the PNW is to observe the recommended 10- to 15-year rotation

Corresponding author: Lindsey J. du Toit, Email: dutoit@wsu.edu

Accepted for publication 7 October 2014.

http://dx.doi.org/10.1094/PDIS-08-14-0804-RE

(C) 2015 The American Phytopathological Society interval between spinach seed crops (14). This rotation interval does not always lessen Fusarium wilt risk, however. Cases of near-total yield losses have occurred in fields that had not had a spinach seed crop for 18 years or longer, whereas some fields considered highrisk for Fusarium wilt based on shorter rotation intervals have developed only mild wilt symptoms (L. J. du Toit, personal observation). Because spinach seed is one of the more financially lucrative crops in the maritime PNW (32), and fields that meet the rotation requirement are increasingly scarce, growers and seed companies need a more accurate tool for determining when a field may be "safe" for planting. This requires a reliable and accurate method of estimating the inoculum potential of Fusarium wilt in a field.

Inoculum potential is the energy available for substrate (host) colonization at the point of infection, which in turn is a function of pathogen population density and vigor, physico-chemical and microbial properties of the soil, and environmental variables such as soil temperature and precipitation (16). Baker (5) surmised that inoculum potential combined with host susceptibility (disease potential) determines the level of disease risk. One approach to measuring inoculum potential is to estimate the size of the pathogen population through direct measurement. Dilution plating of soil samples onto a selective growth medium is a common method for fungal pathogen quantification (48). This does not work well for $F$. oxysporum f. sp. spinaciae, however, because colonies of the pathogen are morphologically indistinguishable from other formae speciales and nonpathogenic isolates of $F$. oxysporum when plated onto Komada's agar medium, which is semiselective for $F$. oxysporum (25). Differentiating the spinaciae isolates from other $F$. oxysporum formae speciales requires labor- and time-consuming pathogenicity tests (4).

In an attempt to circumvent such testing, a Taqman real-time PCR assay was developed by Okubara et al. (34) to detect and quantify F. oxysporum f. sp. spinaciae in soils via extraction and amplification of DNA with pathogen-specific primers. However, the correlation between the quantity of purported pathogen DNA obtained from soil samples and development of spinach Fusarium wilt in those soils in greenhouse assays was negligible (34). The poor predictive value 
of the real-time PCR assay for Fusarium wilt risk was hypothesized to be due to the very limited quantity of soil that could be processed for DNA extraction (up to $0.8 \mathrm{~g} / \mathrm{sample}$ ), variation in virulence among isolates of $F$. oxysporum f. sp. spinaciae (E. W. Gatch and L. J. du Toit, unpublished data), and/or the high incidence of cross-reaction of the assay with nonpathogenic isolates of $F$. oxysporum (34). Any method of assessing the inoculum potential of soils for spinach Fusarium wilt that is based strictly on quantitative estimates of the pathogen population, without consideration of the influence of soil environment and host susceptibility on disease development, is likely to be inadequate as a risk prediction tool. These limitations of soilborne pathogen DNA quantification have been encountered by others working with prediction of risk for Fusarium wilts and other soilborne diseases of various crops (e.g., 23,36).

Another approach to predicting the risk of soilborne diseases is to complete a bioassay or grow-out test in soil samples collected from the target fields, by planting cultivars of known susceptibility into the soil samples in an environment conducive to disease development. Disease severity is then evaluated at appropriate intervals to calculate a risk index for each soil sample (48). This method of estimating natural inoculum potential can be very effective because the influence of soil environment is taken into account, as demonstrated in studies of pea root rot caused by Aphanomyces euteiches and Fusarium solani f. sp. pisi in the United States and Europe $(29,37,40)$

In developing methods to understand and predict soilborne disease risks, many researchers have observed associations among soil properties and disease severity, leading to a large body of literature on the characteristics of soils suppressive to certain diseases (e.g., 1,21,31). Soil physical and chemical properties such as macro- and micronutrient availability, $\mathrm{pH}$, cation exchange capacity (CEC), electrical conductivity (EC), organic matter (OM), bulk density, texture analysis, and clay mineralogy, and biological properties such as microbial mass, activity, and diversity have been examined in relation to the conduciveness of soils to plant disease development. Many studies have examined whether these associations can replace timeconsuming bioassays for predicting risk or identifying soils suppressive to a disease (22). For example, Stotzky and Martin (46) found that soils with smectite clay, which has a higher CEC compared with other clay types, were suppressive to Fusarium wilt of banana, while soils without smectite clay were conducive. Lazarovits et al. (26) analyzed relationships between potato common scab and soil edaphic factors such as $\mathrm{OM}, \mathrm{pH}$, mineral nutrients, and CEC to identify scab predictor variables. In examining the relationship among soil factors and occurrence of Aphanomyces root rot in sugar beet fields in southern Sweden, Olsson et al. (35) identified high soil calcium $(\mathrm{Ca})$ as reliably predictive of this disease. A potential limitation of such studies is that correlations detected in one region may not apply to other regions where the disease occurs (26). The objectives of this study were to: 1) develop a soil bioassay as a prediction tool for Fusarium wilt risk for spinach seed growers in the PNW; and 2) evaluate soil chemical and physical characteristics in relation to the severity of spinach Fusarium wilt to identify quantifiable factors that could aid in the prediction of Fusarium wilt risk.

\section{Materials and Methods}

Fusarium wilt soil bioassay development. Preliminary experiments were completed to establish optimal conditions for cultivation of spinach plants in field soils, as well as for rapid development of spinach Fusarium wilt in a greenhouse environment. Based on spring planting schedules and the timing of spinach seed production contracts, a 6-week window from early January to mid-February was established for receiving and processing growers' soil samples and completing the soil bioassay. The following were identified as necessary components of an effective Fusarium wilt soil bioassay: 1) instructions to collect soil in a manner that represents the target field accurately; 2) indicator spinach parent lines representing the possible range in Fusarium wilt susceptibility; 3) conditions conducive to the growth of healthy spinach seedlings and rapid development of Fusarium wilt to facilitate delivery of results to stakeholders prior to spring field preparation for planting; 4) validation of results to assess the predictive value of the bioassay; and 5) arrangement for annual iterations and adjustment of the bioassay to better account for the influence of weather, crop rotation, and other farming practices on the risk of Fusarium wilt.

To develop a bioassay for differentiating soils with various levels of Fusarium wilt risk, a randomized complete block (RCB) design with five replications was used to evaluate three factors: 1) soils sampled from each of three fields considered high, medium, and low risk for Fusarium wilt based on spinach seed crop rotation intervals; 2) three soil heat treatments to generate further differences in Fusarium wilt risk; and 3) three proprietary spinach parent lines characterized as highly susceptible, moderately susceptible, and moderately resistant to Fusarium wilt (10-12). The high-risk field had been in spinach seed production just two months before collecting soil for this experiment, the medium-risk field had an 8-year rotation out of spinach seed production, and the low-risk field had not been planted to a spinach crop for approximately 12 years. The high-risk soil was a Mount Vernon very fine sandy loam, the medium-risk soil a Skagit silt loam, and the low-risk soil a Sedro Woolley silt loam (44).

Approximately 100 liters of the soil collected from each field was heated in a 200 liter Pro-Grow SS-30 model electric soil sterilizer (Pro-Grow Supply Corp., Brookfield, WI) for: 1) $1.5 \mathrm{~h}$ at approximately $65^{\circ} \mathrm{C}$, 2) $1.5 \mathrm{~h}$ at $65^{\circ} \mathrm{C}$ followed by $2 \mathrm{~h}$ at $80^{\circ} \mathrm{C}$, or 3 ) not heat-treated. Two control soil treatments also were included: 1$)$ the high-risk soil autoclaved twice at $121^{\circ} \mathrm{C}$ and $1.1 \mathrm{~kg} / \mathrm{cm}^{2}$ for 30 min with $24 \mathrm{~h}$ between each autoclaving; and 2) soil collected from an orchard in Skagit Co, WA, that had never been planted to a spinach seed crop. These control treatments were not subjected to the two heat treatments. To maintain a three-way factorial arrangement of treatments for statistical analyses, the control treatments were excluded from the analyses of variance (ANOVAs) and used instead as a baseline for comparison with the remaining soil treatment combinations. The soil for each treatment combination was sieved (6.3 mm-diameter-aperture sieve) prior to heat treatment and planting. Each soil sample was stored at $4^{\circ} \mathrm{C}$ and mixed manually just before planting.

The bioassay was conducted in a greenhouse with air temperature set at 24 to $27^{\circ} \mathrm{C}$ during the day and 21 to $24^{\circ} \mathrm{C}$ at night, and supplemental lighting provided for $10 \mathrm{~h} /$ day. Plants were fertigated with General Purpose 20-20-20 fertilizer (Plant Marvel, Chicago, IL) injected into the irrigation water at 1:100 for applying nitrogen at $200 \mathrm{ppm}$. Seeds were treated with thiram (Thiram42-S, Bayer CropScience, Research Triangle Park, NC) and mefenoxam (Apron XL LS, Syngenta, Basel, Switzerland) at 521 and $20 \mathrm{ml} / 100 \mathrm{~kg}$ seed, respectively, for control of Rhizoctonia and Pythium, respectively, to avoid confounding symptoms from these pathogens with Fusarium wilt assessments. Bifenthrin (Talstar P granular insecticide, FMC Corp., Philadelphia, PA) was applied to the soil surface in each pot $(0.11$ $\mathrm{kg} / \mathrm{m}^{2}$ ) for control of cranefly (Tipula paludosa Meigen) larvae, and watered into the soil. Bacillus thuringiensis (Berliner, 1915) subspecies israelensis strain AM65-52 (Gnatrol WDG, Valent BioSciences Corp., Libertyville, IL) was applied four times during the bioassay at a rate of $2 \mathrm{~g} / \mathrm{liter}$ for control of fungus gnat larvae (Mycetophilidae and Sciaridae). A weekly application from a rotation of insecticides was used to control thrips (Thrips spp. and/or Frankliniella spp.) in this and subsequent bioassays, including imidacloprid (Provado 1.6F, Bayer CropScience, applied at $45 \mathrm{ml} / \mathrm{ha}$ ), Beauveria bassiana (Balsamo) Vuillemin (Botanigard 22WP, Laverlam International, Butte, MT, applied at $2.4 \mathrm{~g} /$ liter), spinosad (Success 480SC, Dow AgroSciences, Indianapolis, IN, applied at $50 \mathrm{ml} / 1,000$ liters), and acephate (Orthene 97, AmVac Chemical Co., Newport Beach, CA, applied at $1.2 \mathrm{~g} /$ liter $)$.

Planting, disease assessment, and spinach measurement. Before filling each 12-cm-diameter $\times 12-\mathrm{cm}$-tall plastic pot (Anderson Die, Portland, OR) with soil, the six holes in the bottom of each pot were covered with flat-bottomed marbles $(1.25 \mathrm{~cm}$ diameter, Panaceae Products, Columbus, $\mathrm{OH}$ ) to prevent loss of soil during irrigation. Eight seeds per pot were sown approximately $1 \mathrm{~cm}$ deep in the soil in each pot, and seedlings thinned to four per pot. Fusarium wilt 
symptoms were rated 28, 35, and 42 days after planting (DAP) on a 0 -to- 5 ordinal wilt scale, where: $0=$ no visible wilt symptoms; $1=$ a few flaccid older leaves; 2 = approximately $25 \%$ of the leaves chlorotic and wilting; $3=$ approximately $50 \%$ of the leaves chlorotic and wilting; 4 = approximately $75 \%$ of the leaves chlorotic and wilting; and $5=$ plant dead due to wilt. The number of seedlings in each category was recorded at each assessment. A wilted seedling was collected approximately 21 to 28 DAP from a pot of each treatment combination in which wilting was observed, along with an asymptomatic seedling. The crown and roots of each seedling were surfacesterilized in $1.2 \% \mathrm{NaOCl}$; triple-rinsed in sterilized, deionized water; dried; cut into pieces; and plated onto potato dextrose agar (Difco Laboratories, Detroit, MI) amended with chloramphenicol (cPDA) and onto chloramphenicol-amended water agar (cWA). Hyphal tip transfers were made from candidate colonies of $F$. oxysporum growing from the tissue pieces, and verified as $F$. oxysporum by examination with a compound microscope ( $80 \times$ to $640 \times$ magnification) (27). At 47 DAP, aboveground spinach biomass was measured by cutting the stem of all plants in each pot at the soil line, combining the plants from each pot into a paper bag, drying the plants at $35^{\circ} \mathrm{C}$ for 3 to 7 days, and recording the dry biomass.

Chemical and microbial evaluation of soils. A soil analysis for nitrate $\left(\mathrm{NO}_{3}{ }^{-}\right)$- and ammonium $\left(\mathrm{NH}_{4}{ }^{+}\right)$-nitrogen $(\mathrm{N})$, phosphorus $(\mathrm{P})$, calcium $(\mathrm{Ca})$, magnesium $(\mathrm{Mg})$, sulfur $(\mathrm{S})$, boron $(\mathrm{B})$, zinc $(\mathrm{Zn})$, manganese $(\mathrm{Mn})$, copper $(\mathrm{Cu})$, iron $(\mathrm{Fe}), \mathrm{pH}, \mathrm{CEC}, \mathrm{EC}, \mathrm{OM}$, and buffer $\mathrm{pH}$ was completed at Soiltest Farm Consultants, Inc. (Moses Lake, WA) using a $100 \mathrm{~g}$ subsample collected immediately prior to planting each soil treatment combination. Three additional subsamples of $50 \mathrm{~g}$ soil were collected prior to planting, air-dried, crushed, and passed through a $1 \mathrm{~mm}$-aperture sieve for enumeration of $F$. oxysporum and Verticillium dahliae (Kleb.). The latter causes Verticillium wilt of spinach $(10,13)$. To quantify colony-forming units (CFU) of $F$. oxysporum/g air-dried soil, a $10 \mathrm{~g}$ subsample was added to $100 \mathrm{ml}$ sterilized, $0.1 \%$ water agar in a $240 \mathrm{ml}$ glass French square, agitated for $10 \mathrm{~min}$ on a rotary shaker at $250 \mathrm{rpm}$, and diluted serially to a $10^{-2}$ concentration. A $0.5 \mathrm{ml}$ aliquot of each of the $10^{-1}$ and $10^{-2}$ dilutions was distributed across the surface of three replicate plates of modified Komada's agar medium $(25,42)$ using a sterilized glass rod. The plates were incubated on a laboratory bench at room temperature $\left(25 \pm 2^{\circ} \mathrm{C}\right)$ in ambient light. Colonies typical of $F$. oxysporum (dense, fluffy, white to pale-pink aerial mycelium) were enumerated 7 and 14 days after plating. To assay soil for $V$. dahliae, a sterilized glass salt shaker with a metal screw cap was used to sprinkle $1 \mathrm{~g}$ of dried, crushed, and sieved soil of each subsample onto each of ten 95-mm-diameter plates of NP-10 agar medium, which is semiselective for Verticillium $(20,45)$. After 28 days of incubation in the dark at $26^{\circ} \mathrm{C}$, colonies typical of $V$. dahliae were enumerated using a dissecting microscope (20x to $100 \times$ magnification), and the number of microsclerotia/g soil calculated. After removing spinach plants for biomass measurement, soil was collected from three replicate pots per treatment, mixed, dried, crushed, sieved, and used for postbioassay enumeration of $F$. oxysporum.

The bioassay was repeated with the following modifications. Instead of orchard soil, soil collected from a field in Skagit Co. that had been fumigated with methyl bromide:chloropicrin $(57: 43 \%$ at 3,274 liters/ha) was used as a negative control treatment. The eight seeds sown in each pot were not thinned to four seedlings. When rating wilt severity, each plant was assessed individually at weekly intervals to record the temporal progression of wilt.

2010 grower soil bioassay. The protocol developed in the preliminary bioassays was used to evaluate the risk of Fusarium wilt for soil samples submitted by growers and seed company representatives from each of 26 fields in northwestern Washington that were under consideration for planting spinach seed crops in spring 2010. The same three female spinach parent lines were planted in each soil sample submitted, as well as three control soils: a positive control soil consisting of the same high risk soil used in the preliminary bioassays, an intermediate risk soil prepared by subjecting the high risk soil to steam treatment at approximately $65^{\circ} \mathrm{C}$ for $1.5 \mathrm{~h}$ followed by $80^{\circ} \mathrm{C}$ for $2 \mathrm{~h}$ in the electric soil sterilizer, and a negative control soil developed by autoclaving the high risk soil for $30 \mathrm{~min}$ at $121^{\circ} \mathrm{C}$ and $1.1 \mathrm{~kg} / \mathrm{cm}^{2}$ on each of two consecutive days with $24 \mathrm{~h}$ between autoclavings. The treatment design included a two-way factorial arrangement of three spinach inbred lines and 29 soil samples (26 grower soil samples and three control soils). The experimental design was a RCB with five replicate blocks.

Soil samples from fields in Skagit and Snohomish counties were submitted in December 2009 or early January 2010. Two 19-liter buckets of soil were requested per field. Samples were stored at approximately 10 to $15^{\circ} \mathrm{C}$. The two buckets of soil per sample were mixed thoroughly and spread on a plastic tarp on a greenhouse bench to dry until the soil was passed through a $6.3-\mathrm{mm}$-aperture sieve. A subsample of each soil was sent to Soiltest Farm Consultants for nutrient analysis as described for the preliminary bioassays.

The greenhouse was set to a $10 \mathrm{~h}$ day/14 h night schedule with supplemental lighting during the day. The air temperature was set at 22 to $25^{\circ} \mathrm{C}$ during the day and 19 to $22^{\circ} \mathrm{C}$ at night. Seeds of the three spinach parent lines were treated with Thiram 42-S and Apron XL LS, and insect pest management carried out as described previously. Fifteen pots were filled with the appropriate soil sample and planted on 15 January 2010 with eight seeds of the appropriate spinach parent line (five pots per parent line). The total number of emerged seedlings was recorded, and severity of Fusarium wilt symptoms rated 21, 28, 35 , and 42 DAP using the same assessment scale as for the preliminary bioassays. Since Fusariuum wilt symptoms usually do not develop on spinach plants until at least 10 to 14 days after planting, even under highly conducive conditions for the disease, spinach seedlings that developed wilting or damping-off symptoms within the first 2 weeks of planting were collected for isolations to determine the potential causal agent of the symptoms. However, few of the isolates obtained from these seedlings were tested for pathogenicity. A sample of wilted seedlings was collected on 25 January (one seedling) and 1 February (nine seedlings) from each of the three inbred lines, and isolations for potential plant pathogens completed as described previously. Spinach plants were harvested 56 to 59 DAP, and aboveground dried biomass measured. A subsample (approximately $50 \mathrm{~g}$ ) of each soil was dried and sieved for enumeration of $F$. oxysporum and $V$. dahliae as described for the preliminary bioassays.

Each disease rating was converted to a disease index for each plot (pot) using the following weighted average formula, and then analyzed using ANOVA:

$$
\begin{aligned}
& \text { Fusarium wilt index } \\
& =\frac{\sum(\text { severity rating } \times \text { number of seedlings in that rating })}{(\text { total number of emerged seedlings }) \times 5}
\end{aligned}
$$

Rank transformation of raw disease index data were performed prior to ANOVA due to nonhomogeneous variances (43). In the statistical model, soils, spinach parent lines, and the interactions of these factors were considered fixed effects. Replications were considered random effects, including any interaction terms with replications. ANOVAs were calculated for each dependent variable using SAS Version 9.2 (SAS Institute, Cary, NC).

Growers and seed company representatives observed results of the soil bioassay on 13 February 2010 (29 DAP), in advance of the annual March meeting when seed company representatives finalize decisions about the locations of seed crops (the seed crop "pinning" meeting) to ensure minimum pollen isolation standards are enforced. In addition, 14 fields tested in the bioassay and planted with spinach seed crops in 2010 were evaluated in summer 2010 to determine whether the Fusarium wilt severity observed in each seed crop corresponded with the Fusarium wilt severity rating in the bioassay. The incidence and severity of Fusarium wilt were assessed along a transect selected randomly in each of these fields.

2011 grower soil bioassay. A grower soil bioassay was carried out again in the winter of 2010/2011 with soil samples submitted by growers and seed company representatives from each of 42 fields in Skagit and Clallam counties. Each soil sample was mixed using a gas-operated soil shredder (Royer Model 10, Oshkosh, 
WI). As described previously, five pots per spinach parent line were filled with soil from each field, and spinach seed was planted on 14 January 2011. A subsample of each soil was subjected to nutrient analysis as described previously. The same high-risk soil used in the 2010 bioassay was used as a positive control treatment. To produce a low-risk control soil, a sample of the high-risk soil was heat-treated at $56^{\circ} \mathrm{C}$ for $1 \mathrm{~h}$ with a steam-operated soil pasteurizer (38). To produce the intermediate-risk soil, the high-risk soil was steamed at $40^{\circ} \mathrm{C}$ for $1 \mathrm{~h}$. Greenhouse conditions and pest management practices were as described for the 2010 grower soil bioassay, with the exception that from 25 January to 7 February 2011, the air temperature was set at 20 to $23^{\circ} \mathrm{C} /$ day and 18 to $21^{\circ} \mathrm{C} /$ night during warm, sunny days. On 26 January, isolations were completed as described previously from seven wilted seedlings, each from a different soil sample, and similarly from nine seedlings on 7 February. Plants were rated for Fusarium wilt 21, 28, and 35 DAP, and harvested for aboveground biomass 47 to 48 DAP. A subsample of $50 \mathrm{~g}$ of each soil was then dried and sieved for enumeration of $F$. oxysporum and V. dahliae as described for the 2010 grower soil bioassay. At 38 DAP, growers and seed company representatives observed results of the bioassay by comparing the severity of Fusarium wilt of spinach plants in the soils they submitted relative to the control soils. During summer 2011, visits were made to 11 of the 42 fields evaluated in the bioassay that had been planted to spinach seed crops to determine whether the Fusarium wilt severity observed in each seed crop corresponded to that predicted by the bioassay.

2012 grower soil bioassay. Soil samples were submitted from 39 fields in December 2011, and the bioassay was set up on 11 January 2012 using the same protocol as for the 2011 bioassay. Fusarium wilt symptoms were rated 21,28 , and $35 \mathrm{DAP}$, and spinach plants were harvested and dried 44 DAP. The greenhouse lighting regime and pest management practices were as described for the 2010 bioassay. The air temperature was set to 22 to $25^{\circ} \mathrm{C} /$ day and 24 to $26^{\circ} \mathrm{C} /$ night until 25 January, after which the temperature was set at 24 to $26^{\circ} \mathrm{C} /$ day and 22 to $25^{\circ} \mathrm{C} /$ night to promote development of Fusarium wilt. Isolations from 11 wilted seedlings were carried out on 25 January, and from an additional three seedlings on 6 February.

In addition to soil samples submitted by growers and seed company representatives, soil samples were collected from a four-year spinach Fusarium wilt field trial $(17,18)$ to serve as validation soils for the bioassay. The spinach seed crop trial was carried out from 2009 to 2012 in a grower-cooperator's field in Skagit Co. that had a very high risk of Fusarium wilt. The effects on Fusarium wilt development of three rates of agricultural limestone $\left(97 \% \mathrm{CaCO}_{3}\right.$ applied at $0,2.24$, and $4.48 \mathrm{t} / \mathrm{ha}$ ) applied to the same plots each year were evaluated in a 2012 spinach seed crop trial. The spinach plots demonstrated a wide range in Fusarium wilt severity as a result of the annual limestone treatments. Soil samples were collected in December 2011 from three replicate plots for each rate of limestone amendment These nine soil samples were processed and planted in the 2012 bioassay along with the 39 grower soil samples. To further assess the predictive value of the bioassay, each of the three indicator parent lines was planted into $1 \mathrm{~m}$ of row in each of 10 fields evaluated in the 2012 bioassay and subsequently planted to a spinach seed crop in 2012. Two of the 10 fields were predicted to have a high risk of Fusarium wilt based on the bioassay results. Spinach plants in the 1-m-long female test plots were assessed visually for Fusarium wilt severity on 27 July using the same 0 -to-5 rating scale as in the bioassay.

2013 grower soil bioassay. In the 2013 grower soil bioassay, 40 soil samples were received from growers and seed company representatives. Soil processing, planting of the three spinach inbred lines, disease and soil microbial assessments, soil nutrient analyses, and spinach biomass measurement were completed as described for the 2010 to 2012 soil bioassays.

Correlation and regression analyses. Pearson's correlation coefficients were calculated to discern relationships among the various soil properties measured and severity of Fusarium wilt observed in the growers' soil bioassays completed each year from 2010 to 2013. Stepwise multiple regressions were performed using PROC REG in SAS Version 9.2 to identify significant models that explained the variability in disease severity among soils. Soil samples from fields that had no prior history of spinach seed production, the control soil treatments, and soils with very poor spinach growth due to residual herbicide effects were excluded from the regression analyses, reducing the number of soil samples used in the analyses from 147 to 121 .

\section{Results}

Preliminary soil bioassays. Data analyses for the preliminary soil bioassay revealed significant main effects of the level of risk of Fusarium wilt for each soil, Fusarium wilt susceptibility of the spinach inbred lines, and soil heat treatment on Fusarium wilt severity ratings 28, 35, and 42 DAP; AUDPC; and spinach plant biomass, except for the soil heat treatment main effect on wilt severity 42 DAP (Table 1). There was a significant interaction between spinach inbred line and soil Fusarium wilt risk level for wilt severity measured 28, 35 , and 42 DAP, as well as AUDPC and plant biomass (Table 1). Colonies with morphology typical of $F$. oxysporum were isolated

Table 1. Probability values from the analyses of variance (ANOVAs) for the fixed effects of soil Fusarium wilt risk, spinach inbred line susceptibility to Fusarium wilt, and soil heat treatment on Fusarium wilt ratings 28, 35, and 42 days after planting (DAP); area under the disease progress curve (AUDPC); and aboveground spinach biomass in a preliminary greenhouse soil bioassay for assessing the risk of spinach Fusarium wilt

\begin{tabular}{|c|c|c|c|c|c|c|}
\hline \multirow[b]{2}{*}{ ANOVA factor ${ }^{a}$} & \multicolumn{4}{|c|}{ Fusarium wilt severity } & \multicolumn{2}{|c|}{ Spinach biomass } \\
\hline & 28 DAP $^{b}$ & 35 DAP & 42 DAP & AUDPC & g/plant $t^{c}$ & g/pot \\
\hline Soil Fusarium wilt risk & $<0.0001 *$ & $<0.0001 *$ & $<0.0001 *$ & $<0.0001 *$ & $<0.0001 *$ & $<0.0001 *$ \\
\hline Spinach inbred line & $<0.0001 *$ & $<0.0001 *$ & $<0.0001 *$ & $<0.0001 *$ & $0.0071 *$ & $0.0016^{*}$ \\
\hline Soil heat treatment & $0.0209 *$ & $0.0240 *$ & 0.0551 & $0.0247 *$ & $0.0027 *$ & $0.0004 *$ \\
\hline Soil-by-inbred & $0.0055^{*}$ & $0.0085^{*}$ & $0.0003 *$ & $0.0197 *$ & $0.0037^{*}$ & $0.0020 *$ \\
\hline Soil-by-heat treatment & 0.3360 & 0.9354 & 0.9234 & 0.6456 & 0.2777 & 0.1531 \\
\hline Inbred-by-heat treatment & 0.7133 & 0.9139 & 0.9014 & 0.8640 & 0.6050 & 0.8048 \\
\hline Soil-by-inbred-by-heat & 0.7374 & 0.5088 & 0.6364 & 0.6197 & 0.4392 & 0.3216 \\
\hline $\mathrm{R}^{2}$ & 0.8678 & 0.8644 & 0.8761 & 0.8646 & 0.7946 & 0.8056 \\
\hline $\mathrm{CV}$ & 21.91 & 22.79 & 21.72 & 23.01 & 28.45 & 27.68 \\
\hline
\end{tabular}

a The experimental design was a randomized complete block with three factors: 1) soil from fields with 12-, 8-, and 0-year rotations out of a spinach seed crop, characterized as low-, medium-, and high-risk for Fusarium wilt, respectively; 2) female inbred spinach lines highly susceptible, moderately susceptible, or moderately resistant to spinach Fusarium wilt; and 3) soil heated for $1.5 \mathrm{~h}$ in an electric soil sterilizer at $65^{\circ} \mathrm{C}$ followed by $2 \mathrm{~h}$ at $80^{\circ} \mathrm{C}$ (high heat), for $1.5 \mathrm{~h}$ at $65^{\circ} \mathrm{C}$ (low heat), or not heated (nontreated). See Gatch (17) for details. $\mathrm{R}^{2}=$ coefficient of determination. $\mathrm{CV}=$ coefficient of variance. Raw data for each variable was subjected to nonparametric rank transformation due to heterogeneous variances and/or nonnormal distribution of residuals. $*=$ significant at $P \leq 0.05$.

${ }^{\mathrm{b}}$ For each of five replications/treatment combination, four spinach plants per pot were rated for severity of Fusarium wilt symptoms on a 0 -to-5 scale, with $0=$ healthy plant, and $5=$ dead plant. Ratings were subsequently converted to a 0-to- 1 index, with 1 representing maximum Fusarium wilt severity.

${ }^{c}$ Dried, aboveground spinach biomass was calculated for all plants in a pot $(\mathrm{g} / \mathrm{pot})$ or per plant $(\mathrm{g} / \mathrm{plant})$. 
from every seedling sampled, including the single asymptomatic seedling, although five of the 24 seedlings assayed were also infected with Rhizoctonia spp.

Spinach plants in the high-risk soil had greater Fusarium wilt severity than plants in the medium-risk soil, which had greater Fusarium wilt severity than plants in the low-risk soil (Fig. 1A) at each of the three weekly severity ratings and for AUDPC (AUDPC of 26.4, 9.1, and 1.5 for the high-, medium-, and low-risk soils, respectively). Plants in the high-risk soil were smaller (average $0.03 \mathrm{~g} / \mathrm{pot}$ ) compared with plants in the medium- and low-risk soils (1.27 and $1.24 \mathrm{~g} /$ pot, respectively) (Fig. 1B). Spinach plants in the two negative control soils, one autoclaved and one from an orchard with no history
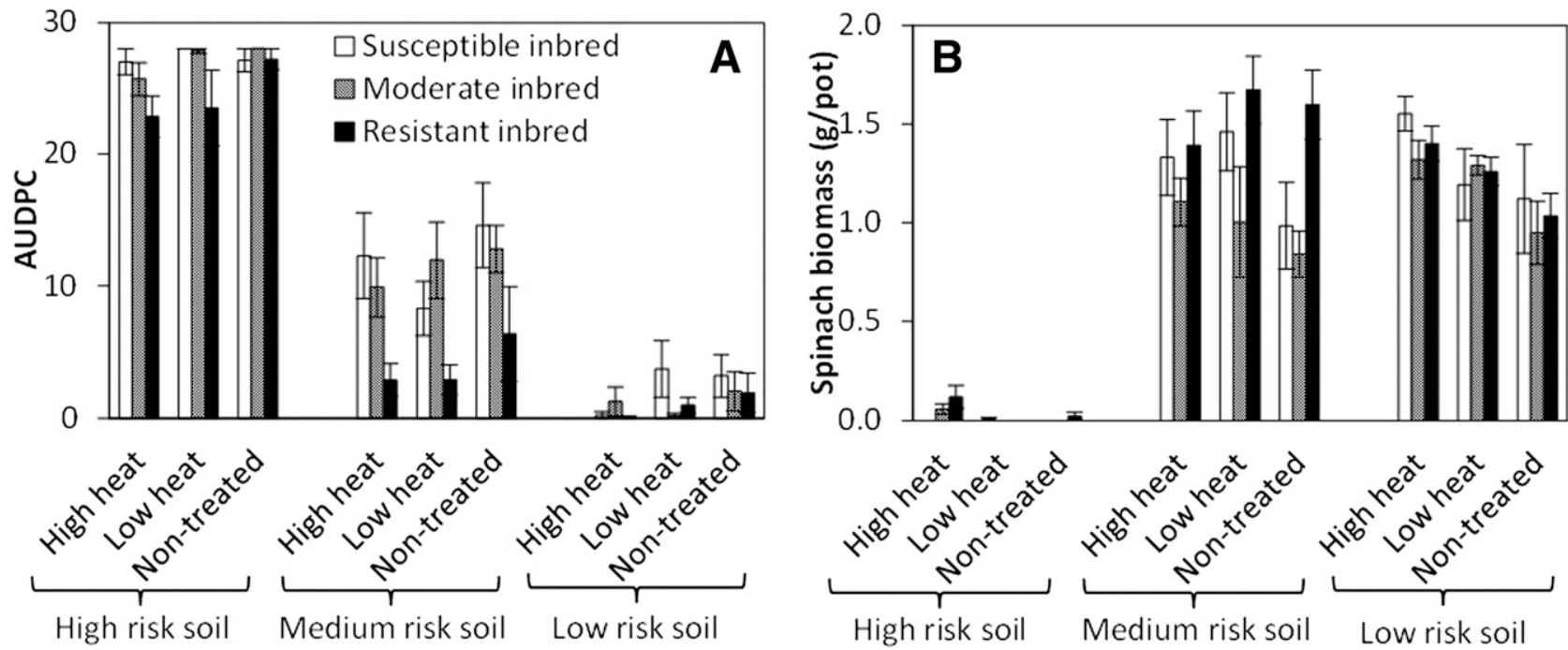

Fig. 1. Effects of soil Fusarium wilt risk level, soil heat treatment, and spinach inbred line on area under the disease progress curve (AUDPC) (A) based on weekly severity ratings, and spinach biomass ( $\mathrm{g} / \mathrm{pot})(\mathrm{B})$ in a preliminary soil bioassay for assessing the risk of Fusarium wilt. The experimental design was a randomized complete block with three factors: 1) soil collected from fields with 12,8 , and 0 years since a spinach seed crop was last planted, characterized as low, medium, and high risk for Fusarium wilt, respectively; 2) female inbred spinach lines highly susceptible, moderately susceptible, or moderately resistant to spinach Fusarium wilt; and 3) soil heated for $1.5 \mathrm{~h}$ in an electric soil sterilizer at $65^{\circ} \mathrm{C}$ followed by $2 \mathrm{~h}$ at $80^{\circ} \mathrm{C}$ (high heat), for $1.5 \mathrm{~h}$ at $65^{\circ} \mathrm{C}$ (low heat), or not heated (nontreated). Refer to Gatch (17) for details. Each data point is the mean \pm standard error of five replicate plots, with four seedlings per pot.

Table 2. Properties of soils evaluated in preliminary soil bioassays, as well as a 2010 growers' soil bioassay, for determining the risk of spinach Fusarium wilt

\begin{tabular}{|c|c|c|c|c|c|c|c|c|c|c|c|c|c|c|c|}
\hline \multirow[b]{2}{*}{ Variable $^{x}$} & \multicolumn{3}{|c|}{$\begin{array}{c}\text { Low risk soil } \\
\text { (12 year rotation) }\end{array}$} & \multicolumn{3}{|c|}{$\begin{array}{l}\text { Medium risk soil } \\
\text { (8 year rotation) }\end{array}$} & \multicolumn{3}{|c|}{$\begin{array}{c}\text { High risk soil } \\
\text { (0 year rotation) }\end{array}$} & \multicolumn{4}{|c|}{ Negative control soils } & \multirow[b]{2}{*}{$\begin{array}{l}\text { Intermediate } \\
\text { control soil }\end{array}$} & \multirow[b]{2}{*}{$\begin{array}{c}\text { Positive } \\
\text { control soil }\end{array}$} \\
\hline & Nontreated & $\begin{array}{l}\text { Low } \\
\text { heat }\end{array}$ & $\begin{array}{l}\text { High } \\
\text { heat }\end{array}$ & Nontreated & $\begin{array}{l}\text { Low } \\
\text { heat }\end{array}$ & $\begin{array}{l}\text { High } \\
\text { heat }\end{array}$ & Nontreated & $\begin{array}{l}\text { Low } \\
\text { heat }\end{array}$ & $\begin{array}{l}\text { High } \\
\text { heat }\end{array}$ & $\begin{array}{l}\text { Auto- } \\
\text { claved }\end{array}$ & $\begin{array}{c}\text { Orch- } \\
\text { ard }\end{array}$ & $\begin{array}{l}\text { Fumi- } \\
\text { gated }\end{array}$ & $\begin{array}{c}\text { Steam- } \\
\text { past. }\end{array}$ & & \\
\hline $\mathrm{pH}$ & 6.3 & 6.3 & 6.3 & 6.8 & 6.6 & 6.6 & 5.7 & 5.8 & 5.8 & 5.5 & 6.3 & 6.4 & 5.6 & 5.5 & 5.4 \\
\hline Buffer pH & 6.9 & 6.9 & 6.9 & 6.9 & 6.8 & 6.8 & 6.6 & 6.6 & 6.5 & 6.5 & 6.6 & 6.6 & 6.4 & 6.4 & 6.5 \\
\hline $\mathrm{NO}_{3}(\mathrm{mg} / \mathrm{kg})$ & 3.6 & 3.7 & 3.6 & 3.9 & 5.5 & 5.0 & 5.6 & 4.9 & 4.3 & 4.2 & 10.1 & 8 & 9.9 & 15.0 & 25.9 \\
\hline $\mathrm{NH}_{4}(\mathrm{mg} / \mathrm{kg})$ & 1.3 & 1.1 & 5.2 & 1.8 & 3.9 & 6.2 & 1.4 & 1.3 & 6.3 & 6.0 & 2.6 & . & 8.3 & 3.2 & 2.2 \\
\hline$P(\mathrm{mg} / \mathrm{kg})$ & 80 & 81 & 82 & 192 & 192 & 192 & 273 & 273 & 309 & 208 & 142 & 102 & 132 & 338 & 292 \\
\hline $\mathrm{K}(\mathrm{mg} / \mathrm{kg})$ & 227 & 227 & 238 & 401 & 412 & 416 & 259 & 276 & 271 & 275 & 404 & 275 & 378 & 358 & 476 \\
\hline $\mathrm{Ca}(\mathrm{meq} / 100 \mathrm{~g})$ & 3.8 & 3.6 & 3.8 & 10.0 & 9.1 & 9.3 & 3.6 & 3.6 & 3.6 & 4.1 & 8.3 & 127 & 3.4 & 3.4 & 2.7 \\
\hline Mg (meq/100 g) & 0.7 & 0.7 & 0.7 & 1.5 & 1.4 & 1.4 & 0.6 & 0.6 & 0.6 & 0.7 & 1.6 & 132 & 0.7 & 0.7 & 0.6 \\
\hline $\mathrm{S}(\mathrm{mg} / \mathrm{kg})$ & 6 & 5 & 9 & 12 & 16 & 16 & 4 & 6 & 5 & 14 & 10 & 3 & 15 & 13 & 15 \\
\hline B (mg/kg) & 0.24 & 0.24 & 0.32 & 0.71 & 0.49 & 0.49 & 0.08 & 0.10 & 0.12 & 0.36 & 0.43 & 0.60 & 0.32 & 0.28 & 0.26 \\
\hline $\mathrm{Fe}(\mathrm{mg} / \mathrm{kg})$ & 73 & 72 & 71 & 84 & 84 & 79 & 35 & 46 & 42 & 53 & 116 & 62 & 88 & 88 & 63 \\
\hline $\mathrm{Mn}(\mathrm{mg} / \mathrm{kg})$ & 1.2 & 1.1 & 3.3 & 2.6 & 3.0 & 3.5 & 1.2 & 1.8 & 3.5 & 54.7 & 2.6 & 2.0 & 14.3 & 4.0 & 3.8 \\
\hline $\mathrm{Zn}(\mathrm{mg} / \mathrm{kg})$ & 0.8 & 0.8 & 0.9 & 1.6 & 1.4 & 1.2 & 1.2 & 1.6 & 1.5 & 2.1 & 5.1 & 4.5 & 4.0 & 3.7 & 2.2 \\
\hline $\mathrm{Cu}(\mathrm{mg} / \mathrm{kg})$ & 3.9 & 3.8 & 3.8 & 6.9 & 6.3 & 5.4 & 1.2 & 1.5 & 1.3 & 1.5 & 12.5 & 3.3 & 2.2 & 2.2 & 2.0 \\
\hline CEC (meq/100 g $)^{\mathrm{y}}$ & 11.6 & 8.4 & 10.8 & 19.7 & 17.2 & 16.6 & 10.4 & 9.8 & 9.7 & 10.3 & 15.6 & 9.0 & 10.9 & 11.9 & 9.8 \\
\hline $\mathrm{OM}(\%)$ & 2.0 & 1.9 & 2.0 & 3.0 & 3.4 & 3.2 & 2.7 & 2.7 & 2.8 & 3.0 & 4.0 & 2.3 & 3.2 & 3.2 & 2.8 \\
\hline $\mathrm{EC}(\mathrm{mmhos} / \mathrm{cm})$ & 0.29 & 0.26 & 0.29 & 0.47 & 0.47 & 0.44 & 0.29 & 0.21 & 0.23 & 0.55 & 0.60 & 0.20 & 0.12 & 0.22 & 0.43 \\
\hline $\begin{array}{l}\text { F. oxysporum } \\
\text { pretrial } \\
(\mathrm{CFU} / \mathrm{g})^{\mathrm{z}}\end{array}$ & 1,978 & 1,400 & 622 & 2,022 & 1,044 & 355 & 4,556 & 3,200 & 2,133 & 0 & 711 & 133 & 0 & 733 & 2,556 \\
\hline $\begin{array}{l}\text { F. oxysporum } \\
\text { posttrial } \\
(\mathrm{CFU} / \mathrm{g})^{\mathrm{z}}\end{array}$ & 8,215 & 6,896 & 9,281 & 4,570 & 7,052 & 6,193 & 11,422 & 11,214 & 12,014 & 0 & 4,786 & 363 & - & - & - \\
\hline
\end{tabular}

x Soils were collected in fall 2009 from fields in Skagit County, WA. The low-, medium-, and high-risk soils were from fields that had not had a spinach seed crop for 12,8 , and 0 years preceding the bioassay, respectively. The negative control soils represented different approaches used to achieve soils without the spinach Fusarium wilt pathogen, Fusarium oxysporum f. sp. spinaciae. The autoclaved soil consisted of the high-risk soil autoclaved twice at $121^{\circ} \mathrm{C}$ and $1.1 \mathrm{~kg} / \mathrm{cm}^{2}$ for $30 \mathrm{~min}$ with $24 \mathrm{~h}$ between autoclavings. The orchard soil had never had a spinach seed crop. The fumigated soil was from a research field trial that had been fumigated with methyl bromide/chloropicrin (57:43\% at 3,274 liters/ha). The steam pasteurized soil (steam-past.) consisted of the high-risk soil steamed at $60^{\circ} \mathrm{C}$ for $1 \mathrm{~h}$. The intermediate control soil in the 2010 bioassay was made by heating the high risk soil with an electric sterilizer (SS-30, Pro-Grow Supply Corp.) at $65^{\circ} \mathrm{C}$ for $1.5 \mathrm{~h}$ and at $80^{\circ} \mathrm{C}$ for $2 \mathrm{~h}$. A subsample of each soil was sent to Soiltest Farm Consultants, Inc. (Moses Lake, WA) for nutrient analysis. Refer to Gatch (17) for details.

y $\mathrm{CEC}=$ cation exchange capacity, $\mathrm{EC}=$ electrical conductivity, and $\mathrm{OM}=$ organic matter.

z Population of $F$. oxysporum (including possible nonpathogenic isolates and other formae speciales which could not be distinguished morphologically from strains of the spinach pathogen) quantified in soils before (pretrial) and after (posttrial) the preliminary bioassay by dilution plating on Komada's agar medium (25). Fungal colonies typical of $F$. oxysporum were counted 7 and 14 days after plating. 
of spinach seed production, had a mean biomass of 1.64 and 1.90 g/pot, respectively. Plants of the susceptible and moderate spinach lines had similar Fusarium wilt severity ratings that were greater than that of the resistant line throughout the trial, with AUDPC values of 13.8 and 13.3 versus 9.9 , respectively. This effect varied with the level of risk of Fusarium wilt for each soil, however (Table 1 and Fig. 1A). In the low-risk soil, there was no difference in Fusarium wilt severity among spinach lines, while in the medium-risk and, to a lesser extent, the high-risk soils, the susceptible and moderate inbreds had significantly more severe wilt compared with the resistant line (Table 1 and Fig. 1A). Wilt was so severe in the high-risk soil that by 35 and 42 DAP there was no significant differentiation in wilt severity among the three inbred lines. Conversely, in the low-risk soil there was negligible wilt, regardless of inbred line (Fig. 1A). A similar interaction between spinach line and soil Fusarium wilt risk was observed for spinach biomass per pot and biomass per plant (Table 1 and Fig. 1B).

The high-heat soil treatment reduced Fusarium wilt severity at 28 and 35 DAP, but not at 42 DAP, reduced AUDPC, and increased spinach biomass compared with nontreated soil, but the effects were smaller than the effects of soil Fusarium wilt risk and spinach parent line (Table 1). The AUDPC of spinach plants in soil exposed to the high and low heat treatments was 11.4 and 11.9, respectively, compared with 13.7 for nontreated soil. The heat treatments reduced F. oxysporum populations in each soil: from 1,978 to $622,2,022$ to 355 , and 4,556 to 2,133 CFU/g in nontreated versus high-heat-treated soil of the low-, medium-, and high-risk soils, respectively; but these reductions were not detected by the end of the trial (Table 2).

Similar results were observed in the repeat preliminary bioassay (data not shown), with several exceptions. In the second preliminary bioassay, spinach plants in the medium-risk soil had significantly greater biomass than plants in the high- or low-risk soils. While in the first preliminary bioassay, the highly and moderately susceptible inbreds did not differ significantly in Fusarium wilt severity, in the second preliminary bioassay the susceptible inbred had significantly more severe Fusarium wilt than the moderate inbred, which in turn had more severe Fusarium wilt than the resistant inbred.

2010 to 2012 grower soil bioassays: Fusarium wilt and plant growth assessments. Results for each of the bioassays of growers' soil samples are depicted in Figures 2 to 4 in order of increasing Fusarium wilt severity, based on the mean Fusarium wilt index for each soil sample averaged over all three inbred lines on the final rating. Control soils (high, medium, and low risk of Fusarium wilt) are shown at the far right in each figure.

2010 soil bioassay. Of 26 soil samples submitted by eight stakeholders for the inaugural growers' soil bioassay, plants in four of the soils exhibited abnormal growth characterized by stunting and chlorosis. This was attributed to a soil $\mathrm{pH}$ too low (4.8) in one soil to foster normal growth of spinach (7), and phytotoxicity from residual herbicides for the other three soils (T. W. Miller, Extension Weed Scientist, Washington State University, personal communication). Fusarium wilt could not be assessed for plants growing in these soils. A species of Pythium was isolated from a wilting seedling of the moderately susceptible inbred collected on 25 January. Of the nine wilting seedlings collected on 1 February, seven (four of the susceptible inbred, two of the moderate inbred, and one of the resistant inbred) were infected with $F$. oxysporum and one plant of the resistant inbred was infected with a Pythium sp.

Severity of Fusarium wilt symptoms observed in the bioassay was affected significantly by soil sample and spinach inbred line, as well as the interaction of these factors (Table 3). A wide range in apparent Fusarium wilt risk was observed among the 26 submitted soil samples, even though the samples were all from fields under consideration for planting a spinach seed crop in 2010. By the final rating 42 DAP, the severity of Fusarium wilt averaged across inbred lines was $>0$ for every soil, and ranged from 0.01 to 0.95 with a mean of 0.49 (Fig. 2A). Fusarium wilt severity for each inbred line and soil sample increased over the 42 days of the bioassay, although in five soil samples the final Fusarium wilt index was $<0.2$ (soils 13, 7 , 25, 16, and 14; Table 4 and Fig. 2A).

Table 3. Probability values from the analyses of variance (ANOVAs) for the fixed effects of soil sample and spinach inbred line susceptibility to Fusarium wilt on Fusarium wilt severity ratings, area under the disease progress curve (AUDPC), and plant biomass in Fusarium wilt soil bioassays

\begin{tabular}{|c|c|c|c|c|c|c|c|}
\hline \multirow[b]{2}{*}{ Year and ANOVA factorw } & \multicolumn{5}{|c|}{ Fusarium wilt severity } & \multicolumn{2}{|c|}{ Spinach biomass } \\
\hline & 21 DAPx $^{x}$ & 28 DAP & 35 DAP & 42 DAP & AUDPC & g/plant ${ }^{\mathbf{y}}$ & g/pot \\
\hline \multicolumn{8}{|l|}{2010} \\
\hline Soil & $<0.0001$ & $<0.0001$ & $<0.0001$ & $<0.0001$ & $<0.0001$ & $<0.0001$ & $<0.0001$ \\
\hline Spinach inbred & $<0.0001$ & $<0.0001$ & $<0.0001$ & $<0.0001$ & $<0.0001$ & $<0.0001$ & $<0.0001$ \\
\hline Soil-by-inbred & $<0.0001$ & $<0.0001$ & $<0.0001$ & $<0.0001$ & $<0.0001$ & $<0.0001$ & $<0.0001$ \\
\hline $\mathrm{R}^{2}$ & 0.8044 & 0.8810 & 0.8999 & 0.8967 & 0.8982 & 0.8633 & 0.8633 \\
\hline $\mathrm{CV}$ & 27.17 & 21.76 & 20.13 & 20.49 & 20.48 & 23.71 & 23.71 \\
\hline Transformation & Rank & Rank & Rank & Rank & Rank & Rank & Rank \\
\hline \multicolumn{8}{|l|}{2011} \\
\hline Soil & $<0.0001$ & $<0.0001$ & $<0.0001$ & $-z$ & $<0.0001$ & $<0.0001$ & $<0.0001$ \\
\hline Spinach inbred & $<0.0001$ & $<0.0001$ & $<0.0001$ & - & $<0.0001$ & 0.2483 & 0.2353 \\
\hline Soil-by-inbred & $<0.0001$ & $<0.0001$ & $<0.0001$ & - & $<0.0001$ & $<0.0001$ & $<0.0001$ \\
\hline $\mathrm{R} 2$ & 0.5719 & 0.7930 & 0.8294 & - & 0.8278 & 0.7144 & 0.8103 \\
\hline $\mathrm{CV}$ & 26.84 & 24.40 & 24.13 & - & 23.88 & 34.44 & 28.07 \\
\hline Transformation & Rank & Rank & Rank & - & Rank & Rank & Rank \\
\hline \multicolumn{8}{|l|}{2012} \\
\hline Soil & $<0.0001$ & $<0.0001$ & $<0.0001$ & - & $<0.0001$ & $<0.0001$ & $<0.0001$ \\
\hline Spinach inbred & $<0.0001$ & $<0.0001$ & $<0.0001$ & - & $<0.0001$ & $<0.0001$ & $<0.0001$ \\
\hline Soil-by-inbred & $<0.0001$ & $<0.0001$ & $<0.0001$ & - & $<0.0001$ & $<0.0001$ & $<0.0001$ \\
\hline $\mathrm{R}^{2}$ & 0.7193 & 0.8662 & 0.9025 & - & 0.8893 & 0.8846 & 0.8513 \\
\hline $\mathrm{CV}$ & 23.29 & 22.25 & 19.57 & - & 20.85 & 21.91 & 24.85 \\
\hline Transformation & Rank & Rank & Rank & - & Rank & Rank & Rank \\
\hline
\end{tabular}

${ }^{\mathrm{w}}$ The experimental design each year was a randomized complete block with two factors: 1) soil samples; and 2) female spinach inbred lines highly susceptible, moderately susceptible, or moderately resistant to spinach Fusarium wilt. See Gatch (17) for details. $\mathrm{R}^{2}=$ coefficient of determination. CV $=$ coefficient of variance. Transformation $=$ raw data subjected to nonparametric rank transformation due to heterogeneous variances and/or non-normal distribution of residuals. * = significant at $P \leq 0.05$.

${ }^{x}$ For each replication, up to eight plants per pot were each rated 21, 28, 35, and 42 days after planting (DAP) for severity of Fusarium wilt on a 0 -to-5 scale, with $0=$ healthy plant, and $5=$ dead plant due to Fusarium wilt (17). Ratings were converted to a 0 -to- 1 index, with 1 representing maximum Fusarium wilt development (all plants dead).

y Dried, aboveground spinach biomass for all plants in a pot $(\mathrm{g} / \mathrm{pot})$ or $/ \mathrm{plant}(\mathrm{g} / \mathrm{plant})$.

$z_{-}=$No rating for that interval as the bioassay had been terminated. 
Overall, plants of the susceptible inbred line had more severe Fusarium wilt than plants of the moderate line, which had more severe Fusarium wilt than plants of the resistant line at each rating and for AUDPC (AUDPC of 16.5, 9.6, and 6.1, respectively) (Table 4), but these effects varied among the soil samples (Table 3 and Fig. 2B). For example, at $35 \mathrm{DAP}$, the moderate and resistant inbred lines in soil 1 did not differ significantly in severity of Fusarium wilt (index of 0.17 and 0.15 , respectively), but both had less severe wilt than the susceptible inbred (index of 0.76) (Fig. 2B). Soil 27, the high-risk control soil, had such severe wilt for all three inbred lines that there were no significant differences in severity among inbreds. In contrast, the Fusarium wilt inoculum potential of soils 7 and 13 was so low that mild wilt symptoms were observed only for plants of the susceptible inbred line (Fig. 2B).

Spinach biomass (g/plant and g/pot) was affected significantly by soil sample and spinach inbred line, as well as the interaction of these two factors (Table 3). The resistant and moderate inbred lines had greater biomass compared with the susceptible line (mean of 3.19 and 3.35 versus $2.70 \mathrm{~g} /$ pot, respectively) (Table 4), but this effect was also dependent on the soil sample (Table 3). In soils with a low risk index for Fusarium wilt, the resistant line typically had smaller plants (less biomass) than the moderate and susceptible inbred lines (data not shown). As Fusarium wilt severity increased, this reversed, so that plants of the resistant inbred line were larger than plants of the moderate and susceptible inbreds (data not shown). Despite these differences, the overall mean severity index for Fusarium wilt 28 DAP was negatively correlated with spinach biomass $(\mathrm{r}=$ -0.8863 at $P<0.0001$ ) (Figs. 2A and 2C).

Fusarium wilt severity and plant growth were as expected in the control soils designated as high (soil 27), intermediate (soil 28), and low risk (soil 29) for the disease, although plants in the medium-risk soil developed more severe Fusarium wilt than anticipated (Figs. 2A, 2B, and 2C). By the end of the bioassay, the medium- and high-risk soils did not differ significantly in Fusarium wilt severity index when averaged across inbred lines. However, the resistant inbred grown in the medium-risk control soil had significantly less wilt than in the high-risk soil $(0.79$ versus 0.98 , respectively) (Fig. 2B). Plants were larger in the low-risk control soil than in the medium- and high-risk control soils (2.95 versus 0.30 and $0.07 \mathrm{~g} /$ pot, respectively) (Fig. 2C).

2011 soil bioassay. A total of 42 soil samples were submitted by 10 stakeholders for the 2011 Fusarium wilt soil bioassay. Of seven wilted seedlings collected for isolations on 26 January 2011, two were infected with Rhizoctonia spp. (one resistant inbred seedling and one moderate inbred seedling), one was infected with both $R h$ zoctonia and $F$. oxysporum (moderate inbred seedling), three had no fungi isolated (two moderate inbred seedlings and a resistant inbred seedling), and one was infected with an unidentified fungus
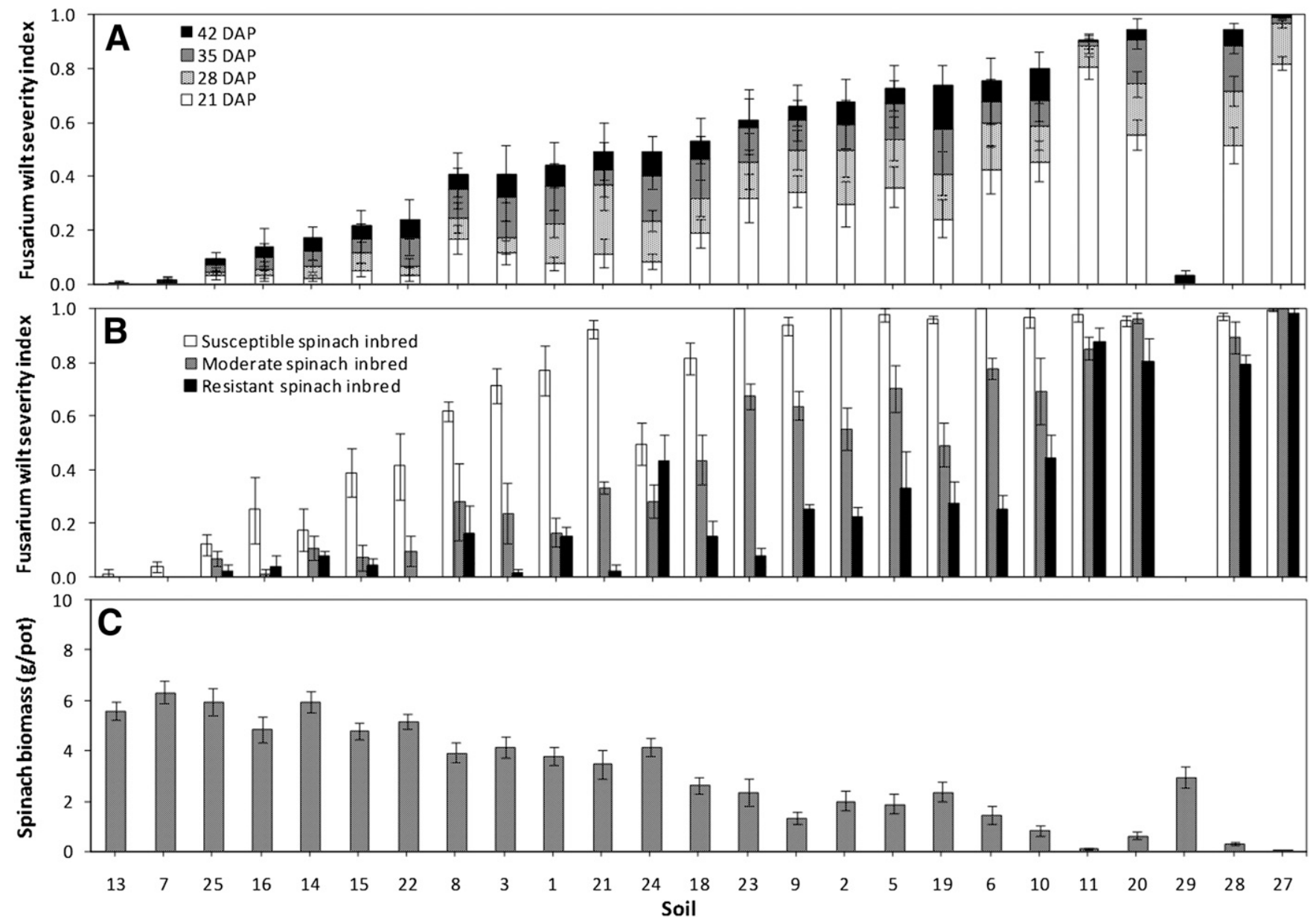

Fig. 2. Effects of 22 growers' field soil samples (soils 1 to 22 ) and three control soils (soils 27 to 29 , representing high, medium, and low risk of spinach Fusarium wilt, respectively) on spinach Fusarium wilt severity index (0-to-1 scale, with $1=$ maximum wilt) measured 21, 28, 35, and 42 days after planting (DAP) and averaged across three inbred lines (A); at $35 \mathrm{DAP}$ for female inbred spinach lines highly susceptible, moderately susceptible, and moderately resistant to spinach Fusarium wilt (B); and aboveground spinach biomass (g/pot) measured 56 to 59 DAP (C) in the 2010 growers' soil bioassay for Fusarium wilt. Details of the bioassay and wilt ratings are described in the main text and by Gatch (17). The experimental design was a randomized complete block with five replications and two factors: 1) soil samples submitted from fields in northwestern Washington by growers or seed company representatives; and 2) female spinach inbred lines highly susceptible, moderately susceptible, or moderately resistant to spinach Fusarium wilt. Each data point is the mean \pm standard error of 15 pots (five replicate pots per inbred line), with up to eight spinach plants evaluated per pot for Fusarium wilt symptoms based on a 0 -to- 5 scale, with $0=$ healthy plant and $5=$ dead plant due to Fusarium wilt. Ratings were converted to a 0 -to- 1 index. Dried, aboveground spinach biomass was measured for all plants per pot. 
wilt severity was observed among the 39 soil samples (Fig. 4A and 4B). Nineteen soils had low to very low risk of Fusarium wilt (mean Fusarium wilt index was $<0.2$ ), and 18 soils had moderate to high risk (mean index $\geq 0.4$ ) (Fig. 4A). However, for some soils that appeared to represent moderate to high risk based on mean index ratings, the soil-by-inbred line interaction provided a superior assessment of the potential for losses to Fusarium wilt. In soils 7, 13, 14, 20, 22, 29 , and 30, for example, Fusarium wilt in the field might be minimal if a resistant inbred line were planted, while severe losses would be expected for a susceptible inbred (Fig. 4B). For soils 1, 2, 10, 16, and 26, even an inbred with partial resistance to Fusarium wilt could pose a risk of losses to Fusarium wilt given the moderate severity of Fusarium wilt observed in the bioassay with the resistant inbred (Fig. 4B).

Mean spinach biomass (g/plant and g/pot) averaged over all soil samples was significantly greater for the moderate and resistant inbred lines compared with the susceptible line (2.01 and 1.90 versus $1.59 \mathrm{~g} /$ pot, respectively) (Table 4). A pattern similar to that observed in the 2010 and 2011 bioassays was apparent in the 2012 soil bioassay, with the susceptible inbred line producing bigger plants in low risk soils compared with the resistant line, and vice-versa in high risk soils (data not shown).

2013 soil bioassay. Results of this fourth bioassay are not included because of limited space and similarity to results of the prior growers' soil bioassays. However, Fusarium wilt ratings, soil nutrient analyses, and other soil properties from the 2013 soil bioassay were included in the correlation and regression analyses described below to provide a more robust sample size for the analyses.

Bioassay validation. 2010. Not all fields sampled and evaluated in the soil bioassay were planted to a spinach seed crop in 2010, although the bioassay samples submitted were all from fields under consideration for planting a spinach seed crop that season. Visual evaluations of spinach seed crops planted in 2010 were conducted for 15 fields from which soil samples were evaluated in the 2010 soil bioassay. Observations of Fusarium wilt severity substantiated results of the bioassay, although no correlation analyses were completed. For one soil, the field appeared to be high risk in the bioassay but very little Fusarium wilt was observed in the spinach seed crop planted in 2010. However, the grower revealed that the planting site had been moved, after observing results of the soil bioassay, to a portion of the field that had been rotated out of spinach seed crops longer than the section of the field sampled for the bioassay. A subsequent greenhouse bioassay completed in August 2010 with soil collected from both parts of this field confirmed what was observed in the growers' spinach seed crop in 2010 (data not shown).

2011. Visual observations were completed for 11 fields evaluated in the 2011 bioassay and planted to spinach seed crops in 2011. Six of these fields (soils 12, 28, 31, 34, 30, and 11) had almost no Fusarium
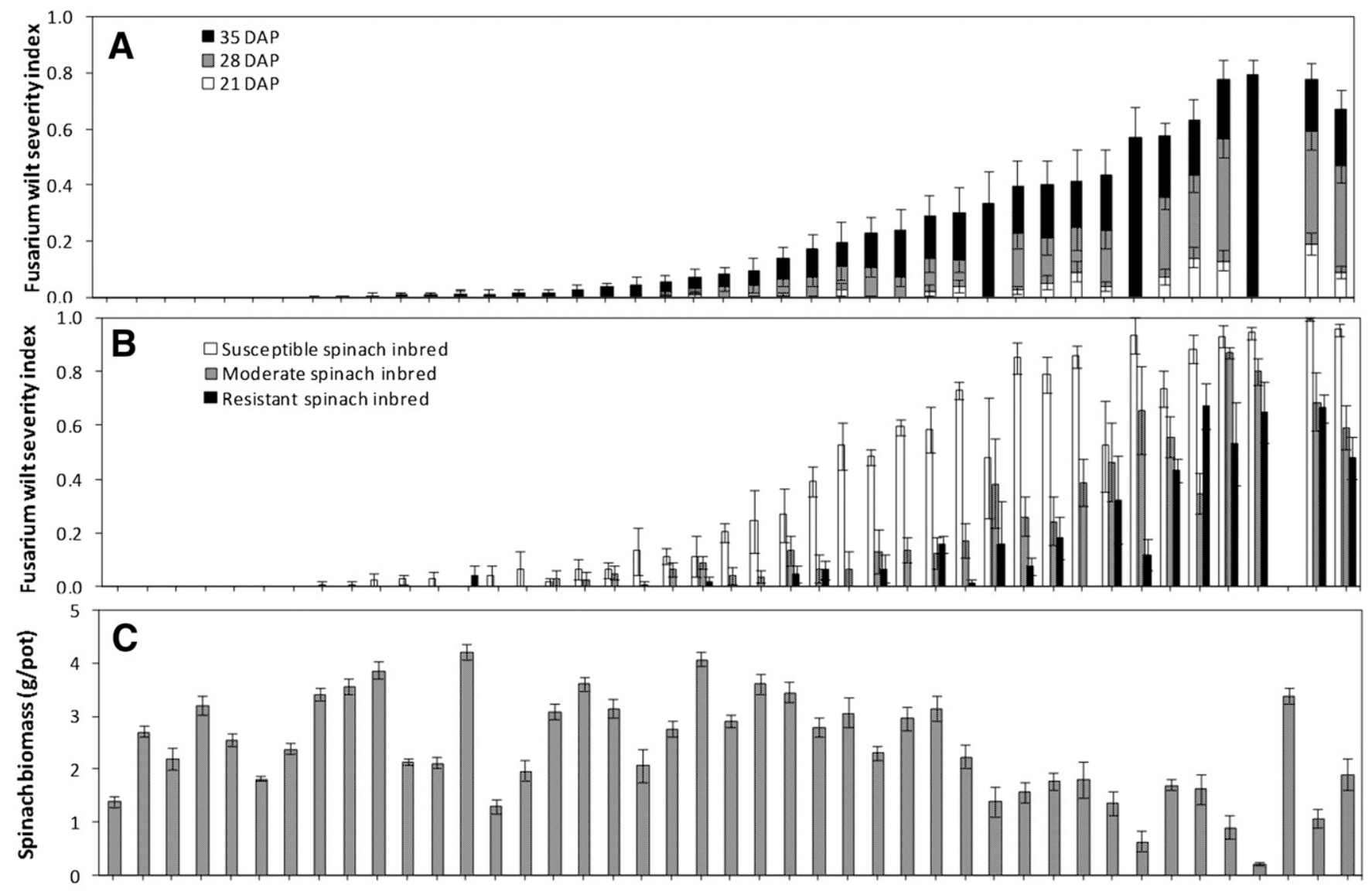

$20344015302831291221181132374222 \quad 2 \quad 3 \quad 44 \quad 927251033113926142313413835433624 \quad 6 \quad 194 \quad 5474645$ Soil

Fig. 3. Effects of 40 growers' field soil samples (soils 1 to 40 ) and three control soils (soils 45, 46, and 47, representing high, medium, and low risk, respectively) on Fusarium wilt severity index (0-to-1 scale, with 1 = maximum wilt) measured 21, 28, and 35 days after planting (DAP) and averaged across three inbred lines (A); at 35 DAP for female inbred spinach lines highly susceptible, moderately susceptible, and moderately resistant to spinach Fusarium wilt (B); and aboveground spinach biomass (g/pot) measured 47 to 48 DAP (C) in the 2011 growers' soil bioassay. Details of the bioassay and wilt ratings are described in the main text and by Gatch (17). The experimental design was a randomized complete block with five replications and two factors: 1) soil samples; and 2) female inbred spinach lines highly susceptible, moderately susceptible, or moderately resistant to spinach Fusarium wilt. Each data point is the mean \pm standard error of 15 pots (five replicate plots per spinach line), with up to eight spinach plants evaluated per pot for Fusarium wilt symptoms on a 0-to- 5 scale, with $0=$ healthy plant and $5=$ dead plant due to Fusarium wilt. Ratings were converted to the 0 -to- 1 index. Dried, aboveground spinach biomass was measured for all plants per pot. Spinach plants in soils $5,20,24,37,41$, and 42 showed symptoms of herbicide residual toxicity that confounded Fusarium wilt ratings until the final rating 35 DAP (A). 
wilt in the bioassay (severity index $<0.1$, Fig. 3A). The absence of Fusarium wilt symptoms in the corresponding spinach seed crops validated these predictions. Three soils $(9,10$, and 33) had a mean Fusarium wilt index $<0.2$, and two (soils 36 and 13) had a mean Fusarium wilt index between 0.2 and 0.5 (Fig. $3 \mathrm{~A}$ ). The incidence and severity of Fusarium wilt in these fields, based on visual assessments of proprietary inbred lines of unknown Fusarium wilt susceptibility planted by the growers, corroborated the bioassay results (data not shown). Test plots in the field corresponding to soil 37 in the 2011 bioassay did not have any symptoms of Fusarium wilt for any of the three inbred lines. This, together with the absence of wilt symptoms in the surrounding inbred lines of the grower's seed crop, was consistent with the low Fusarium wilt risk predicted by the bioassay (Figs. 3A and 3B).

2012. Of the test plots planted in 10 growers' spinach seed crops in 2012, two (soils 18 and 22) were severely damaged by flooding and could not be assessed. Fusarium wilt ratings in the remaining eight test plots for each of the three inbred lines were comparable to those of the corresponding soils in the 2012 bioassay (Figs. 5A and 5B). Plants in soils 12, 15, 19, and 28 had very mild Fusarium wilt symptoms in both the bioassay (Fig. 5B) and the field test plots (Fig. 5A), as well as in the rest of each field planted by the growers with inbred lines of unknown susceptibility to Fusarium wilt. Spinach plants in soils 13, 20, and 21 had moderate to severe Fusarium wilt in the 2012 bioassay (Fig. 5A), depending on the inbred line, and spinach plants in the test plots in the corresponding fields developed similarly moderate to severe Fusarium wilt symptoms (Fig. 5B), along with the commercial spinach seed crops in those fields. In the 2012 bioassay, soil 26 had a moderate risk of Fusarium wilt (Fig. 5B) and yet little wilt was observed in the corresponding field test plots and for the inbred lines planted by the grower (Fig. 5A).

The bioassay results for soil samples collected in November 2011 from a 4-year, limestone-spinach Fusarium wilt field trial were similar to those of the corresponding plots in the 2012 field trial (Table 5; Fig. 6). In the greenhouse soil bioassay, there were highly significant main effects $(P<0.0001)$ of limestone application rate and spinach inbred line on Fusarium wilt severity measured 28 and 35 DAP, and on spinach biomass (Table 5). In the subsequent 2012 spinach field trial, the effects of limestone rate on spinach biomass and Fusarium wilt severity on 9 July were also significant, but less than in the bioassay (Table 5). Limestone rate did not affect Fusarium wilt severity significantly on 31 July in the field trial because the disease was very severe that late in the season (Table 5 and Fig. 6D). However, spinach inbred lines affected Fusarium wilt severity on 9 and 31 July in the field trial, with the most severe wilt observed for the susceptible inbred (Figs. 6B and 6D), but with no significant effect on spinach biomass (Table 5).

In the 2012 greenhouse soil bioassay, Fusarium wilt severity was greatest in soil from plots with no limestone, followed in decreasing order by soil amended with 2.24 and $4.48 \mathrm{t} /$ ha at both 28 and 35 DAP
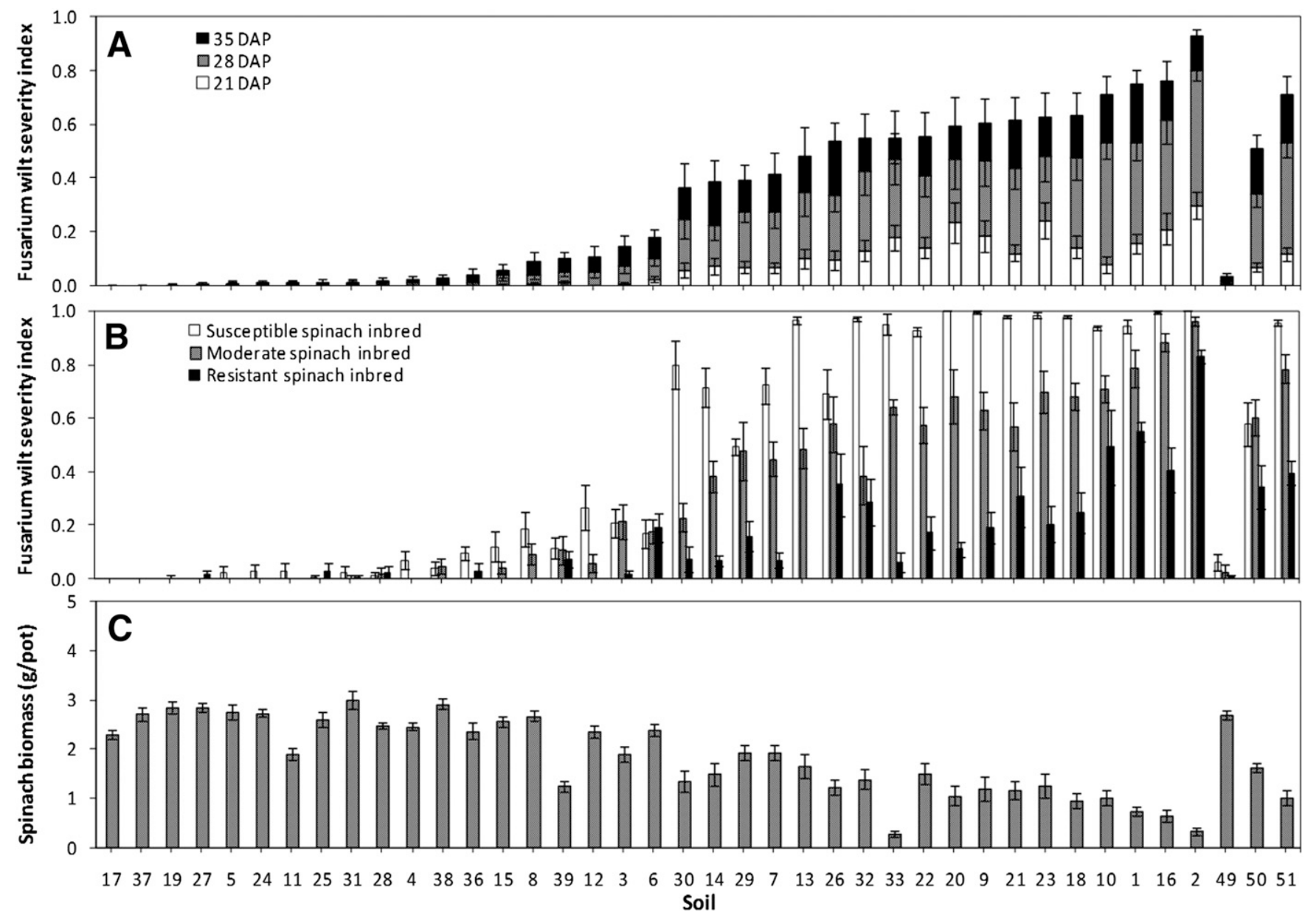

Fig. 4. Effects of 37 growers' field soil samples (soils 1 to 37 ) and three control soils (soils 49 , 50, and 51, representing low, medium, and high risk of spinach Fusarium wilt, respectively) on Fusarium wilt severity index (0-to-1 scale, with 1 = maximum wilt) measured 21, 28, and 35 days after planting (DAP) and averaged across three inbred lines (A); at 35 DAP for female inbred spinach lines highly susceptible, moderately susceptible, and moderately resistant to spinach Fusarium wilt (B); and aboveground spinach biomass ( $\mathrm{g} / \mathrm{pot}$ ) measured 47 to $48 \mathrm{DAP}$ (C) in the 2012 growers' bioassay. Details of the bioassay and wilt ratings are described in the main text and by Gatch (17). The experimental design was a randomized complete block with five replications and two factors: 1) soil samples, and 2) female inbred spinach lines highly susceptible, moderately susceptible, or moderately resistant to spinach Fusarium wilt. Each data point is the mean \pm standard error of 15 pots (five replicate pots per spinach line), with up to eight spinach plants evaluated per pot for Fusarium wilt symptoms on a 0 -to- 5 scale, with $0=$ healthy plant and $5=$ dead plant due to Fusarium wilt. Ratings were converted to a 0 -to-1 index. Dried, aboveground spinach biomass was measured for all plants per plot. 
(Figs. 6A and 6C). In the field, however, the 2.24 and $4.48 \mathrm{t} /$ ha plots did not differ significantly in wilt severity on either 9 or 31 July, although both had less wilt compared with the 0 t/ha plots (Table 5; Figs. 6B and 6D). In both the greenhouse bioassay and field trial, spinach plants in soil amended with $4.48 \mathrm{t}$ limestone/ha were larger than in plots with $2.24 \mathrm{t}$ limestone/ha, which in turn were larger than plants in plots with no limestone (data not shown). In the greenhouse bioassay, the susceptible inbred had more severe wilt (Figs. 6A and 6C) and smaller plants compared with the moderate inbred, which had more severe wilt and smaller biomass compared with the resistant inbred. The same trends were observed in the field (Table 5).

Association of soil properties with Fusarium wilt inoculum potential. Results of the soil nutrient analyses indicated that soils evaluated in these bioassays are typical of the maritime PNW (30): acid (mean pH of 5.70 to 6.15) and with adequate to high levels of most macro- and micronutrients (Table 2). Sixteen soil properties correlated significantly with Fusarium wilt severity $28 \mathrm{DAP}$ in the greenhouse soil bioassays, although the number of significant correlations varied among the three spinach inbred lines (Table 6). The susceptible inbred had the greatest number of significant correlations between Fusarium wilt severity and soil properties (13 soil properties), followed by the moderate (10) and resistant (8) inbreds.

Two macronutrients, $\mathrm{NH}_{4}{ }^{+}-\mathrm{N}$ and $\mathrm{K}$, were significantly positively correlated with Fusarium wilt severity, $\mathrm{NH}_{4}{ }^{+}-\mathrm{N}$ for all three inbreds, and $\mathrm{K}$ for the susceptible and resistant inbreds. $\mathrm{Ca}$ and $\mathrm{B}$ were also positively correlated with Fusarium wilt severity, but only for the moderate and susceptible inbreds for B, and only for the susceptible inbred for $\mathrm{Ca}$. Levels of three acid micronutrients $(\mathrm{Fe}, \mathrm{Mn}$, and $\mathrm{Cu})$ were positively correlated with Fusarium wilt severity: Fe for all three inbreds, $\mathrm{Mn}$ for the resistant inbred, and $\mathrm{Cu}$ for the susceptible inbred. Soil $\mathrm{pH}$ was negatively correlated with Fusarium wilt severity for the susceptible inbred only, while buffer $\mathrm{pH}$ was negatively correlated with Fusarium wilt severity for the susceptible and moderate inbreds. Soil EC was positively correlated with Fusarium wilt severity for the susceptible and moderate inbreds, as was the population of F. oxysporum estimated by dilution plating. The percentages of sand and clay were negatively and positively correlated, respectively, with Fusarium wilt severity for all three inbreds, whereas the percentage of silt was negatively correlated with wilt severity for the moderate inbred only. The number of years since a previous spinach seed crop (spinach rotation interval) was negatively correlated with Fusarium wilt severity for all three inbreds. Variables that did not correlate significantly with Fusarium wilt severity included $\mathrm{NO}_{3}-\mathrm{N}, \mathrm{P}, \mathrm{Mg}, \mathrm{S}, \mathrm{Na}$, $\mathrm{Zn}, \mathrm{CEC}$, and the $V$. dahliae population (data not shown).

Stepwise forward-selection regression analyses revealed the following models, each of which explained the maximum variability associated with severity of Fusarium wilt measured 28 DAP (Y) in the 2010 to 2013 soil bioassays:

$$
\begin{aligned}
& \text { Susceptible inbred: } \mathrm{Y}=-0.4556-0.0172(\text { rotation }) \\
& \quad+0.0854\left(\mathrm{NH}_{4}^{+}-\mathrm{N}\right)-0.3875(\text { soil } \mathrm{pH}) \\
& \quad+0.4037(\text { buffer } \mathrm{pH})+0.0056(\text { sand }) \\
& \quad+0.0245(\text { clay })\left(\mathrm{R}^{2}=0.3396 \text { at } P<0.0001\right) \\
& \text { Moderate inbred: } \mathrm{Y}=1.0777-0.0136(\text { rotation }) \\
& \quad+0.0005(\text { V. dahliae })+0.0563\left(\mathrm{NH}_{4}^{+}-\mathrm{N}\right) \\
& \quad-0.1528(\text { soil } \mathrm{pH})+0.0045(\text { clay })\left(\mathrm{R}^{2}=0.3213 \text { at } P<0.0001\right) \\
& \text { Resistant inbred: } \mathrm{Y}=0.6161-0.0094(\text { rotation }) \\
& \quad+0.0498\left(\mathrm{NH}_{4}^{+}-\mathrm{N}\right)+0.0003(\mathrm{~K}) \\
& \quad-0.0947(\text { soil } \mathrm{pH})\left(\mathrm{R}^{2}=0.2415 \text { at } P<0.0001\right)
\end{aligned}
$$

However, many soil properties exhibited multicollinearity (data not shown). For example, soil CEC was positively correlated with the levels of many soil nutrients. The percentage of sand was negatively correlated with CEC, and thus negatively correlated with the levels of many soil nutrients. Levels of $\mathrm{Fe}$ and $\mathrm{Zn}$, two acid micronutrients that are more available in low $\mathrm{pH}$ soils, were weakly but positively correlated with soil $\mathrm{pH}(\mathrm{r}=0.28$ and 0.21 , respectively, at $P<$ $0.05)$. However, the level of $\mathrm{Mn}$, another acid micronutrient, did not correlate significantly with any other soil property. Although the occurrence of multicollinearity does not violate assumptions for
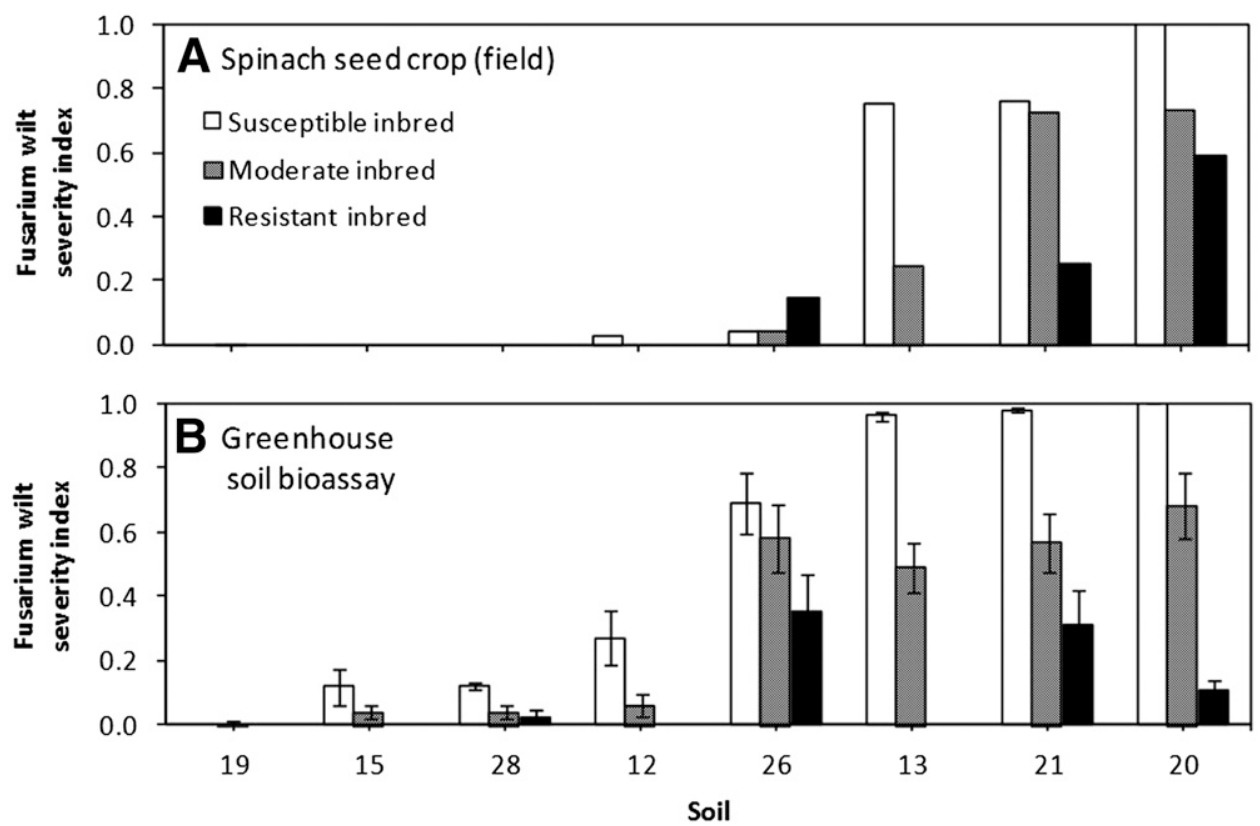

Fig. 5. Results for eight fields (soils 12, 13, 15, 19, 20, 21, 26, and 28) planted with spinach seed crops in 2012 that had been evaluated in the 2012 greenhouse soil bioassay for spinach Fusarium wilt risk (see Fig. 4). Approximately $1 \mathrm{~m}$ of row was planted in each field with each of three female spinach inbred lines highly susceptible, moderately susceptible, and moderately resistant to Fusarium wilt (the same spinach inbred lines used in the soil bioassay). The test plots planted alongside proprietary male and female lines in each field were rated for Fusarium wilt severity on 27 July 2012 using the same 0-to-5 scale (converted to a 0-to-1 index) as in the bioassay (A), and compared with the greenhouse bioassay results for soil sampled from these fields the previous winter (B). Plants in the test plots were incorporated into the soil prior to seed set to avoid contaminating the commercial seed crop. Each data point in the greenhouse soil bioassay (B) represents the mean \pm standard error of five replicate pots of soil, each planted with eight seed of the appropriate spinach line. Data points for the field trial (A) each represent average wilt ratings for all plants of that inbred line in $1 \mathrm{~m}$ of row. 
multiple regression, multicollinearity can complicate interpretation of partial regression coefficients (15).

\section{Discussion}

In this study, a greenhouse soil bioassay for evaluation of spinach Fusarium wilt inoculum potential (risk) was developed, deployed, and validated over the course of 4 years in northwestern Washington, the primary region of spinach seed production in the United States (14). In addition to developing an effective tool for predicting the risk of Fusarium wilt, soil chemical and physical properties that correlated significantly with soil conduciveness to spinach Fusarium wilt were identified as a potential aid in selecting fields suitable for spinach seed crops. Soil bioassays in greenhouse environments have been used for screening host germplasm for resistance to various soilborne diseases, including Fusarium wilts (47). Often such bioassays entail a range of inoculum concentrations in sterilized soil or other growing media to assess host resistance (e.g., 8). When soil is the focus of evaluation, standardized methods can be used in which soil(s) are inoculated with increasing concentrations of the pathogen (2). By growing a susceptible host at different pathogen infestation levels, a disease progress curve can be calculated and compared among soils. This is effective only when there is no initial inoculum in the

Table 5. Probability values from the analyses of variance (ANOVAs) for the fixed effects of limestone application rate and spinach inbred line susceptibility to Fusarium wilt on spinach wilt severity, area under the disease progress curve (AUDPC), and plant biomass in a 2012 soil bioassay and a 2012 spinach seed crop field trial

\begin{tabular}{|c|c|c|c|}
\hline \multirow[b]{2}{*}{ Trial and ANOVA factors ${ }^{\mathrm{x}}$} & \multicolumn{2}{|c|}{ Fusarium wilt severity } & \multirow{2}{*}{$\begin{array}{c}\text { Spinach } \\
\text { biomass }^{\mathrm{z}}\end{array}$} \\
\hline & 28 DAPy & 35 DAP & \\
\hline \multicolumn{4}{|l|}{ Greenhouse soil bioassay } \\
\hline Limestone rate & $<0.0001 *$ & $<0.0001 *$ & $<0.0001 *$ \\
\hline Spinach inbred & $<0.0001 *$ & $<0.0001 *$ & $<0.0001 *$ \\
\hline Limestone-by-inbred & 0.4883 & 0.2122 & 0.3049 \\
\hline $\mathrm{R}^{2}$ & 0.753 & 0.771 & 0.8141 \\
\hline $\mathrm{CV}$ & 30.9 & 28.53 & 17.70 \\
\hline Transformation & - & Rank & Arcsine \\
\hline Spinach seed crop field trial & 9 July & 31 July & Biomass \\
\hline Limestone rate & $0.0204 *$ & 0.0830 & $0.0007 *$ \\
\hline Spinach inbred & $<0.0001 *$ & $0.0020^{*}$ & 0.1488 \\
\hline Limestone-by-inbred & 0.0835 & 0.1948 & 0.9397 \\
\hline $\mathrm{R}^{2}$ & 0.9716 & 0.9837 & 0.8881 \\
\hline $\mathrm{CV}$ & 10.26 & 3.98 & 14.64 \\
\hline Transformation & - & - & - \\
\hline
\end{tabular}

$\bar{x}$ Soil samples were collected in December 2011 from three of five replicate plots of a 4-year limestone/Fusarium wilt spinach seed crop field trial for validation of the greenhouse Fusarium wilt soil bioassay. The samples were processed and planted along with 37 growers' soil samples. Fusarium wilt ratings and spinach biomass measurements in the bioassay were compared with wilt ratings and spinach biomass production for these plots in a 2012 spinach seed crop trial to determine how well the bioassay predicted Fusarium wilt risk. The experimental design was a randomized complete block with three replications and two factors: 1) limestone applied at $0,2.24$, or $4.48 \mathrm{t} / \mathrm{ha}$ for each of three years (2009 to 2011); and 2) female spinach inbred lines highly susceptible, moderately susceptible, or moderately resistant to spinach Fusarium wilt. The field trial was a two-factor, randomized, split block design with the same spinach lines as in the bioassay applied to main plots, and limestone application rates applied to split plots (17). $\mathrm{R}^{2}=$ coefficient of determination. $\mathrm{CV}=$ coefficient of variance. Transformation = when necessary, raw data were subjected to arcsine or nonparametric rank transformation due to heterogeneous variances and/or non-normal distribution of residuals.

${ }^{y}$ In the greenhouse soil bioassay, up to eight plants per pot for each replication were rated for Fusarium wilt on a 0 -to- 5 scale, with $0=$ healthy plant and $5=$ dead plant due to Fusarium wilt. Ratings were converted to a 0-to-1 index with 1 representing maximum Fusarium wilt development (17). Fusarium wilt severity was assessed in the field trial for each plant in $3 \mathrm{~m}$ of each of two rows on the dates indicated, using a similar rating scale and index.

${ }^{\mathrm{z}}$ Dried, aboveground spinach biomass was calculated for all plants in a pot (g/pot) in the greenhouse soil bioassay. In the field trial, biomass was measured by harvesting and drying whole plants sampled from $1 \mathrm{~m}$ of row per plot. soil, which can be achieved by selecting sites with no history of the disease or pasteurizing or sterilizing soil to eliminate the pathogen. For spinach Fusarium wilt, the former is very difficult in the spinach seed-producing area of northwestern Washington. However, the latter is undesirable because soil sterilization precludes assessment of the contribution of soil microbial communities to disease development or suppression (28). The soil bioassay developed in this study evolved from these considerations and the unique challenges of working with a wind-pollinated seed crop, the placement of which is regulated to maintain genetic purity of the harvested seed in a region with limited agricultural acreage.

The preliminary bioassays demonstrated that spinach can be grown in naturally infested soils in pots in a greenhouse to develop Fusarium wilt in less than 2 months, and that levels of Fusarium wilt risk can be differentiated based on severity of Fusarium wilt as well as spinach biomass. The interaction between spinach inbred line and soil Fusarium wilt risk affected spinach growth (biomass) and revealed differences among inbred lines. In the absence of Fusarium wilt, the resistant inbred produced plants with a smaller, compact frame and dark green leaves compared with the moderate and susceptible inbred lines. In the high-risk soil, plants of the resistant inbred had much less severe wilt and, thus, more biomass than the susceptible line. These genetic differences in plant size were independent of the degree of susceptibility to Fusarium wilt, and confounded interpretation of the biomass results, particularly in low-risk soils. This underscores the importance of using indicator lines with similar horticultural properties in a bioassay, and monitoring both disease development and plant growth.

The bioassay was first deployed as a risk prediction service for spinach seed stakeholders in 2010, and annually thereafter. Soil samples from 147 growers' fields in northwestern Washington were submitted for Fusarium wilt risk assessment from 2010 to 2013, and the bioassay continues to be offered to spinach seed producers in the PNW region annually for selection of fields suitable for spinach seed crops. The fields submitted were all under consideration for a spinach seed crop the season following the assay, yet differed greatly in Fusarium wilt risk. Using three inbred lines that possessed a range in Fusarium wilt susceptibility typical of what growers might encounter with proprietary inbred lines they are contracted to grow was invaluable for risk characterization. The bioassay illustrated that for some medium-risk fields, it may be safe to plant a spinach seed crop with inbred lines moderately resistant to Fusarium wilt. However, in other fields even a partially resistant line may not hold up against the inoculum potential of those soils. Both scenarios are possible with soils of similar Fusarium wilt risk when the risk is averaged across inbreds, but disparate responses in some fields for the three inbred lines gave a far more accurate assessment of risk. This underlines the quandary that growers often face in lacking knowledge of the susceptibility to Fusarium wilt of the inbred lines they are contracted to grow, regardless of what they may understand about the Fusarium wilt risk of a field based on results of the bioassay. To help address this problem, a screening service to evaluate spinach parent lines for resistance to Fusarium wilt has been offered annually at the WSU Mount Vernon NWREC in conjunction with the Fusarium wilt soil bioassay.

Despite such inherent limitations to assessing the risk of Fusarium wilt, the bioassay has provided valuable information about soil Fusarium risk for stakeholders. Growers have continued to submit soil samples annually, even with implementation of a $\$ 200$ fee per field for the bioassay. Growers and seed company representatives have reported changes in decisions regarding the location of spinach seed crops as a result of the bioassay, primarily by avoiding fields identified as high risk for Fusarium wilt in the bioassay.

In some studies on the development of bioassays for soilborne disease prediction in other cropping systems, validation has been relatively straightforward (e.g., 39). Researchers can designate fields to evaluate, sample, and assay, and then plant the bioassay indicator cultivar(s) in a field trial following the bioassay to compare results. However, this was not possible with the bioassay for spinach seed crops in northwestern Washington. The placement of spinach seed 

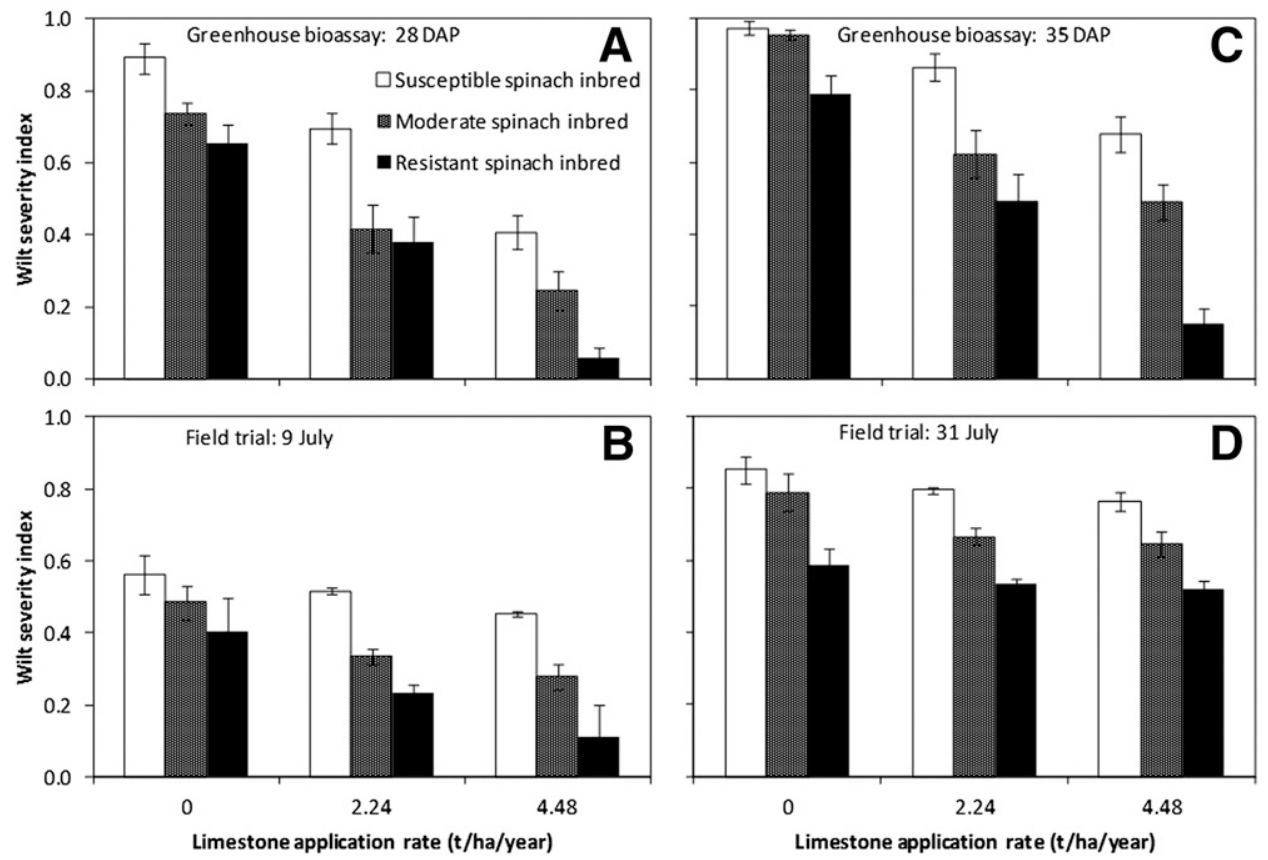

Fig. 6. Comparison of Fusarium wilt severity ratings from a greenhouse soil bioassay (A and C) for assessing Fusarium wilt risk with results of a 2012 spinach seed crop field trial (C and D). Soil samples were collected in November 2011 from plots in a 4-year limestone/Fusarium wilt field trial in Skagit County, WA, in which limestone was applied at 0, 2.24, or 4.48 tha to the same plots each year from 2009 to $2012(17,18)$. Soils were collected from three replicate plots of each limestone treatment, and evaluated in the $2012 \mathrm{greenhouse}$ Fusarium wilt soil bioassay along with soil samples submitted by growers from 37 fields. A spinach seed crop trial was planted in this field site again in spring 2012, with the same three female spinach inbred lines used in the bioassay (highly susceptible, moderately susceptible, and moderately resistant to Fusarium wilt), and wilt development and spinach growth evaluated through the season. Fusarium wilt severity ratings for these soil samples in the bioassay (A and C) were compared with results from the 2012 field trial (B and D), to assess how well the bioassay predicted levels of Fusarium wilt in the field. Each data point represents the mean \pm standard error of spinach Fusarium wilt severity (0-to-1 scale, where 1 = all plants dead from Fusarium wilt) of 15 pots (five replicate pots per limestone rate) in the greenhouse soil bioassay (A and C), and mean spinach Fusarium wilt severity (0-to-1 scale) for spinach plants growing in three replicate plots in the 2012 field trial (B and D).

Table 6. Pearson's correlation coefficients between soil properties and spinach Fusarium wilt severity ratings measured 28 days after planting in Fusarium wilt soil bioassays completed from 2010 to 2013 using soil sampled from 121 growers' fields in northwestern Washington ${ }^{\mathrm{w}}$

\begin{tabular}{|c|c|c|c|}
\hline \multirow[b]{2}{*}{ Soil property ${ }^{x}$} & \multicolumn{3}{|c|}{ Spinach inbred line susceptibility to Fusarium wilt } \\
\hline & Susceptible & Moderate & Partially resistant \\
\hline $\mathrm{NH}_{4}-\mathrm{N}$ & $0.1844(P=0.0428)^{*}$ & $0.2765(P=0.0021)^{*}$ & $0.2700(P=0.0022)^{*}$ \\
\hline $\mathrm{K}$ & $0.1846(P=0.0427)^{*}$ & $0.1769(P=0.0522)$ & $0.1975(P=0.0299)^{*}$ \\
\hline $\mathrm{Ca}$ & $0.2019(P=0.0264)^{*}$ & $0.1589(P=0.0818)$ & $0.0800(P=0.3832)$ \\
\hline B & $0.3098(P=0.0005)^{*}$ & $0.2618(P=0.0037)^{*}$ & $0.1112(P=0.2247)$ \\
\hline $\mathrm{Fe}$ & $0.3128(P=0.0005)^{*}$ & $0.3066(P=0.0006)^{*}$ & $0.2228(P=0.0141)^{*}$ \\
\hline $\mathrm{Mn}$ & $0.1664(P=0.0681)$ & $0.1313(P=0.1511)$ & $0.2164(P=0.0172)^{*}$ \\
\hline $\mathrm{Cu}$ & $0.2048(P=0.0242)^{*}$ & $0.1229(P=0.1793)$ & $0.1127(P=0.2184)$ \\
\hline $\mathrm{pH}$ & $-0.1949(P=0.0322)^{*}$ & $-0.1572(P=0.0852)$ & $-0.1385(P=0.1298)$ \\
\hline Buffer $\mathrm{pH}$ & $-0.1944(P=0.0326)^{*}$ & $-0.2024(P=0.0260)^{*}$ & $-0.1750(P=0.0549)$ \\
\hline $\mathrm{EC}$ & $0.2986(P=0.0009)^{*}$ & $0.2400(P=0.0075)^{*}$ & $0.1255(P=0.1702)$ \\
\hline Fusarium oxysporum ${ }^{y}$ & $0.2156(P=0.0175)^{*}$ & $0.1900(P=0.0408)^{*}$ & $0.1451(P=0.1124)$ \\
\hline Sand $(\%)$ & $-0.2436(P=0.0071)^{*}$ & $-0.2603(P=0.0039)^{*}$ & $-0.1800(P=0.0483)^{*}$ \\
\hline Clay $(\%)$ & $0.3478(P<0.0001)^{*}$ & $0.3259(P=0.0003)^{*}$ & $0.2113(P=0.0200)^{*}$ \\
\hline Silt $(\%)$ & $0.1650(P=0.0705)$ & $0.2025(P=0.0259)^{*}$ & $0.1487(P=0.1035)$ \\
\hline Spinach rotation interval ${ }^{\mathrm{z}}$ & $-0.3068(P=0.0007)^{*}$ & $-0.3138(P=0.0005)^{*}$ & $-0.2700(P=0.0029)^{*}$ \\
\hline Total significant correlations & 13 & 10 & 8 \\
\hline
\end{tabular}

${ }^{\mathrm{w}}$ The experimental design for each bioassay was a randomized complete block with two factors: 1) soil samples; and 2) female inbred spinach lines highly susceptible, moderately susceptible, or moderately resistant to spinach Fusarium wilt. For each of five replications/treatment combination, up to eight spinach plants per pot were rated for Fusarium wilt on a 0 -to- 5 scale, with $0=$ healthy plant and $5=$ dead plant due to Fusarium wilt. Ratings were converted to a 0 -to- 1 index, with 1 representing maximum Fusarium wilt severity. * = significant at $P \leq 0.05$. Refer to Gatch (17) for details.

x Soil samples were collected by spinach seed growers and seed company representatives from fields in northwestern Washington. A subsample of soil for each field was sent to Soiltest Farm Consultants, Inc. (Moses Lake, WA) for analysis. Only soil properties which correlated significantly with Fusarium wilt severity ratings for one or more spinach inbred lines are shown: ammonium-nitrogen $\left(\mathrm{NH}_{4}{ }^{+}\right)$, potassium $(\mathrm{K})$, calcium $(\mathrm{Ca})$, boron $(\mathrm{B})$, iron $(\mathrm{Fe})$, manganese $(\mathrm{Mn})$, copper $(\mathrm{Cu}), \mathrm{pH}$, buffer $\mathrm{pH}$, and electrical conductivity (EC).

y The population of Fusarium oxysporum was quantified by dilution plating a sample of each soil on Komada's agar medium (25). Fungal colonies typical of F. oxysporum on this medium were counted 7 and 14 days after plating.

${ }^{\mathrm{z}}$ Spinach rotation interval $=$ number of years since the field was planted with a spinach seed crop. 
crops is regulated to ensure pollen isolation among fields, with minimum isolation distances ranging from 0.8 to $8.0 \mathrm{~km}$ depending on genetic similarity of the parent lines. This limits the number of fields in the maritime Pacific Northwest that can be planted to spinach seed crops. Prior to 2012, assessing the predictive value of the soil bioassay for fields with a high risk of Fusarium wilt was not possible because fields identified as high risk in the bioassay were not planted to spinach seed crops by growers. Validation test rows of the three spinach parent lines planted in each of 10 spinach seed crops in fields that had been tested in the bioassay facilitated more direct validation. Comparison of the bioassay results with Fusarium wilt severity observed in corresponding spinach seed crops indicated that the bioassay was a reliable predictor of wilt severity. Most growers amend their fields with 2.24 to $4.48 \mathrm{t}$ limestone/ha a few days or weeks before planting spinach seed crops to suppress spinach Fusarium wilt $(10-12,17,18)$. In the first several years of offering the bioassay to growers, most stakeholders did not want limestone added to the soils they submitted because they wanted to see the "worst-case" scenario for Fusarium wilt risk. Therefore, the severity of Fusarium wilt in growers' fields amended with limestone was likely mitigated compared with the soil bioassay results. This may explain results for soil 26 in the 2012 soil bioassay, which predicted moderate to severe Fusarium wilt, compared with the spinach seed crop planted in that field in 2012, which developed very little wilt. Therefore, the potential exists for over-estimating Fusarium wilt risk with the bioassay. To address this, limestone amendment has been offered as an option to the soil bioassay protocol since 2013 that growers can request to reflect more accurately the widespread preplanting application of limestone by spinach seed growers in the maritime PNW.

A 4-year (2009 to 2012) limestone-mediated Fusarium wilt spinach seed field trial provided another opportunity for validation of the soil bioassay. Disease development in the 2012 field trial mirrored that of the 2012 bioassay for soil sampled from replicate plots of the limestone treatments, but was less severe overall in the field than the bioassay. Differences in Fusarium wilt severity among limestone treatments and spinach inbred lines were more pronounced in the bioassay, reflecting the highly conducive conditions used in the bioassay to induce rapid development of Fusarium wilt. Also, the field plots received an additional limestone amendment in spring 2012, after sampling soil for the bioassay and before planting the 2012 field trial. The decline in Fusarium wilt severity observed with increasing rate of limestone amendment in the field trial was associated with highly significant increases in seed yield (18). Although the bioassay was terminated 5 weeks after planting, Fusarium wilt severity ratings in the bioassay aligned more closely with seed yield than disease severity ratings in the field (data not shown).

Correlation and multiple regression analyses revealed significant relationships among various soil properties and spinach Fusarium wilt severity, but none that could replace the bioassay as a prediction tool for the risk of Fusarium wilt. The significance of the correlation between a given soil variable and Fusarium wilt severity (risk) of that soil was influenced significantly by susceptibility of the spinach inbred line. A greater number of soil variables $(n=13)$ was correlated significantly with wilt development for the susceptible inbred line compared with the moderate and resistant inbred lines $(n=10$ and 8 , respectively). From a risk management perspective, this is desirable because accurate risk prediction is most critical when growers plant susceptible inbreds. The percentages of sand and clay measured by soil texture analysis were negatively and positively correlated with severity of Fusarium wilt, respectively. This was unexpected, since studies of Fusarium wilts of other crops have identified coarse-textured soils as a significant risk for those diseases $(6,21)$, although exceptions have been noted (e.g., 41). Of three acid micronutrients (Fe, Mn, and $\mathrm{Zn}$ ) implicated in Fusarium wilt development in other studies $(24,50)$, only Fe correlated consistently with Fusarium wilt severity in this study for all three inbred lines. This suggests availability of these micronutrients may not be linked as closely to development of Fusarium wilt as demonstrated in other studies, or that other factors such as spinach seed crop rotation interval may mask these relationships.
The negative correlation between rotation intervals for spinach seed crops and Fusarium wilt severity was one of the strongest predictive relationships identified, with correlation coefficients ranging from -0.2988 in 2011 to -0.4732 in 2010 . However, a majority $(>66 \%)$ of the variability in Fusarium wilt severity among 121 soils remained unexplained. For almost every soil assayed, the rotation out of spinach was $\geq 10$ years, and yet many fields demonstrated a very high risk of Fusarium wilt. This underlines the challenges spinach seed growers in the PNW face at identifying fields suitable for spinach seed crops. Persistence of the spinach Fusarium wilt pathogen in soils in this region may reflect the ability of the fungus to colonize roots or debris of one or more crops grown in rotation with spinach (e.g., 3,4,19).

Assessment of relationships among soil properties and severity of spinach Fusarium wilt using stepwise multiple regression yielded models that further revealed the nature of some correlations. Based on the regression equations, for example, if a grower wanted to plant susceptible spinach inbreds in a field that had an 8-year rotation out of spinach seed crops, and keep the Fusarium wilt severity index $<0.2$, the ideal field would have $\leq 15 \%$ clay, a low buffering capacity (high CEC), and a soil $\mathrm{pH}$ raised to 7.2 via limestone amendment. Using the regression equations, the rotation interval required to bring the Fusarium wilt risk of a field to zero for each inbred line, assuming typical values for other soil properties in the equations, is 37,25 , and 21 years for susceptible, moderate, and resistant inbred lines, respectively. However, even the best-fitting regression models only explained $\leq 34 \%$ of the variation in wilt severity observed among the 121 soils assayed. Nonetheless, identification of potential predictor variables can lead to new questions and hypotheses about the ecology of spinach Fusarium wilt. For example, the strong correlation between $\mathrm{NH}_{4}{ }^{+}-\mathrm{N}$ and Fusarium wilt severity justifies further study of $\mathrm{NO}_{3}-\mathrm{N}$ fertilizers as a management tool for spinach Fusarium wilt, as demonstrated for other Fusarium wilts (e.g., 49). Similarly, the significant correlation between soil texture and spinach Fusarium wilt risk should be explored since soil texture can be characterized readily and inexpensively.

No single practice or piece of information will eliminate the risk of this disease in maritime PNW fields, and management of spinach Fusarium wilt will continue to depend on a combination of risk assessment and soil $\mathrm{pH}$ adjustment. The multivariate approach in this study provided an introductory foray into the complex subterranean realm of a spinach seed crop, adding to results of the Fusarium wilt soil bioassay, and enhancing our understanding of factors that influence the risk of spinach Fusarium wilt.

\section{Acknowledgments}

The authors acknowledge excellent technical assistance from Mike Derie, Barbara Holmes, Sarah Meagher, and Ron Dralle. In-kind and financial suppor for this project was received from participating spinach seed companies as well as the Puget Sound Seed Growers' Association; Washington State Commission for Pesticide Registration; a USDA Sustainable Agriculture Research and Education Graduate Student Fellow Grant; a USDA Western Region Integrated Pest Management Grant; the Alfred Chrisitanson Endowed Fellowship; the Robert MacDonald Vegetable Seed Memorial Fund; and PPNS \# 0665, Department of Plant Pathology, College of Agricultural, Human, and Natural Resource Sciences, Agricultural Research Center, Hatch Project Nos. WPN00595 and WPN05595, Washington State University, Pullman, 99164-6430. Tom Gordon and Tim Paulitz are acknowledged for valuable discussion and review of the manuscript.

\section{Literature Cited}

1. Alabouvette, C., Olivain, C., Migheli, Q., and Steinberg, C. 2009. Microbiological control of soil-borne phytopathogenic fungi with special emphasis on wilt-inducing Fusarium oxysporum. New Phytol. 184: 529-544.

2. Alabouvette, C., Raajimakers, J., de Boer, W., Notz, R., Défago, G., Steinberg, C., and Lemanceau, P. 2005. Concepts and methods to assess the phytosanitary quality of soils. Pages 257-269. in: Microbiological Methods for Assessing Soil Quality. J. Bloem, D. W. Hopkins, and A. Benedetti, eds. CABI Publishing, Wallingford, UK.

3. Armstrong, G. M., and Armstrong, J. K. 1976. Common hosts for Fusarium oxysporum formae speciales spinaciae and betae. Phytopathology 66: $542-545$.

4. Armstrong, G. M., and Armstrong, J. K. 1981. Formae speciales and races of Fusarium oxysporum causing wilt diseases. Pages 391-399. in: Fusarium: 
Diseases, Biology, and Taxonomy. R. Cook, ed. Pennsylvania State University Press, University Park, PA

5. Baker, R. 1971. Analyses involving inoculum density of soil-borne plant pathogens in epidemiology. Phytopathology 61:1280-1292.

6. Baker, K. F., and Cook, R. J. 1974. Biological Control of Plant Pathogens. W. H. Freeman and Co., San Francisco, CA.

7. Beattie, J. H. 1937. Production of spinach. United States Department of Agriculture Leaflet No. 128. US Government Printing Office, Washington, DC.

8. Becerra Lopez-Lavalle, L. A., Potter, N., and Brubaker, C. L. 2012. Development of a rapid, accurate glasshouse bioassay for assessing Fusarium wilt disease responses in cultivated Gossypium species. Plant Pathol. 61:1112-1120.

9. Correll, J. C., Morelock, T. E., Black, M. C., Koike, S. T., Brandenberger, L. P., and Dainello, F. J. 1994. Economically important diseases of spinach. Plant Dis. 78:653-660.

10. du Toit, L. J., Derie, M. L., and Brissey, L. M. 2008. Effect of agricultural limestone amendments on Fusarium wilt and Verticillium wilt in a spinach seed crop, 2007. Plant Dis. Manage. Rep. 2:V042.

11. du Toit, L. J., Derie, M. L., Brissey, L. M., and Cummings, J. A. 2007. Evaluation of limestone amendments for control of Fusarium wilt in a spinach seed crop, 2006. Plant Dis. Manage. Rep. 1:V091.

12. du Toit, L. J., Derie, M. L., Gatch, E. W., Brissey, L. M., and Holmes, B. 2011. Effect of agricultural limestone amendments on Fusarium and Verticillium wilts in a spinach seed crop, 2008. Plant Dis. Manage. Rep. 5:V117.

13. du Toit, L. J., Derie, M. L., and Hernandez-Perez, P. 2005. Verticillium wilt in spinach seed production. Plant Dis. 89:4-11.

14. Foss, C. R., and Jones, L. J. 2005. Crop Profile for Spinach Seed in Washington. U.S. Dep. Agric. National Pest Management Centers.

15. Freund, R. J., and Littell, R. C. 1991. SAS System for Regression, 2nd Ed. SAS Institute, Cary, NC.

16. Garrett, S. D. 1970. Pathogenic Root-Infecting Fungi. Cambridge University Press, London.

17. Gatch, E. W. 2013. Management of Fusarium wilt in spinach seed crops in the maritime Pacific Northwest USA. PhD dissertation, Pullman, WA.

18. Gatch, E. W., du Toit, L. J., Derie, M. L., Holmes, B. J., and Brissey, L. M. 2011. Effect of agricultural limestone and nitrogen fertilizers on Fusarium wilt and Verticillium wilt in a spinach seed crop, 2009. Plant Dis. Manage. Rep. 5:V118.

19. Gordon, T. R., Okamoto, D., and Jacobsen, D. J. 1989. Colonization of muskmelon and nonsusceptible crops by Fusarium oxysporum f. sp. melonis and other species of Fusarium. Phytopathology 79:1095-1100.

20. Goud, J. C., and Termorshuizen, J. 2003. Quality of methods to quantify microsclerotia of Verticillium dahliae in soil. Eur. J. Plant Pathol. 109: 523-534.

21. Hoper, H., and Alabouvette, C. 1996. Importance of physical and chemical soil properties in the suppressiveness of soils to plant disease. Eur. J. Soil Biol. 32:41-58.

22. Janvier, C., Villeneuve, F., Alabouvette, C., Edel-Hermann, V., Mateille, T., and Steinberg, C. 2007. Soil health through soil disease suppression: which strategy from descriptors to indicators? Soil Biol. Biochem. 39:1-23.

23. Jiménez-Fernández, D. J., Montes-Borrego, M., Jiménez-Díaz, R. M., NavasCortés, J. A., and Landa, B. B. 2011. In planta and soil quantification of Fusarium oxysporum f. sp. ciceris and evaluation of Fusarium wilt resistance in chickpea with a newly developed quantitative polymerase chain reaction assay. Phytopathology 101:250-262.

24. Jones, J. P., and Woltz, S. S. 1970. Fusarium wilt of tomato: Interaction of liming and micronutrient amendment on disease development. Phytopathology 60:812-813.

25. Komada, H. 1975. Development of a selective medium for quantitative isolation of Fusarium oxysporum from natural soil. Rev. Plant Prot. Res. 8: 114-125.

26. Lazarovits, G., Hill, J., Patterson, G., Conn, K. L., and Crump, N. S. 2007. Edaphic soil levels of mineral nutrients, $\mathrm{pH}$, organic matter, and cation exchange capacity in the geocaulosphere associated with potato common scab. Phytopathology 97:1071-1082.

27. Leslie, J. F., and Summerell, B. A. 2006. The Fusarium Laboratory Manual Blackwell Publishing, Ames, IA

28. Lockwood, J. L. 1964. Soil fungistasis. Annu. Rev. Phytopathol. 2:341-362.

29. Malvick, D. K., Percich, J. A., Pflegler, F. L., Givens, J., and Williams, J. L. 1994. Evaluation of methods for estimating inoculum potential of Aphanomyces euteiches in soil. Plant Dis. 78:361-365.

30. Marx, E. S., Hart, J., and Stevens, R. G. 1996. Soil Test Interpretation Guide. Oregon State University EC 1478, Corvallis, OR.

31. Mazzola, M. 2004. Assessment and management of soil microbial community structure for disease suppression. Annu. Rev. Phytopathol. 42:35-59.

32. McMoran, D. 2011. Skagit County Agriculture Statistics. Washington State University Skagit County Extension. http://skagit.wsu.edu/agriculture/ images/2011AgStats.pdf

33. Metzger, J. D., and Zeevaart, J. A. D. 1985. Spinacia oleracea. Pages 384-392. in: CRC Handbook of Flowering. A. H. Halevy, ed. Vol. IV. CRC Press, Boca Raton, FL.

34. Okubara, P. A., Harrison, L. A., Gatch, E. W., Vandemark, G., Schroeder, K. L., and du Toit, L. J. 2013. Development and evaluation of a TaqMan realtime PCR assay for Fusarium oxysporum f. sp. spinaciae. Plant Dis. 97:927-937.

35. Olsson, A., Persson, L., and Olsson, S. 2011. Variation in soil characteristics affecting the occurrence of Aphanomyces root rot of sugar beet - risk evaluation and disease control. Soil Biol. Biochem. 43:316-323.

36. Ophel-Keller, K., Herdina, O., Curran, J., McKay, A., and Hartley, D. 2008. Development of a routine DNA-based testing service for soilborne diseases in Australia. Austral. Plant Pathol. 37:243-253.

37. Oyarzun, P. J., Dijst, G., and Maas, P. W. Th. 1994. Determination and analysis of soil receptivity to Fusarium solani f. sp. pisi causing dry root rot of peas. Phytopathology 84:834-842.

38. Patzek, L. J., Paulitz, T., Derie, M. L., and du Toit, L. J. Constructing a steam pasteurizer for plant pathology research. Washington State University, Pullman, WA. In preparation.

39. Persson, L., Larsson-Wikström, M., and Gerhardson, B. 1999. Assessment of soil suppressiveness to Aphanomyces root rot of pea. Plant Dis. 83:1108-1112.

40. Reiling, T. P., King, T. H., and Fields, R. W. 1960. Soil indexing for pea root rot and the effect of root rot on yield. Phytopathology 50:287-290.

41. Scher, F. M., and Baker, R. 1980. Mechanism of biological control in a Fusarium-suppressive soil. Phytopathology 70:412-417.

42. Scott, J. C., Gordon, T. R., Shaw, D. V., and Koike, S. T. 2010. Effect of temperature on severity of Fusarium wilt of lettuce caused by Fusarium oxysporum f. sp. lactucae. Plant Dis. 94:13-17.

43. Shah, D. A., and Madden, L. V. 2004. Nonparametric analysis of ordinal data in designed factorial experiments. Phytopathology 94:33-43.

44. Soil Survey Staff, United States Department of Agriculture, Web Soil Survey Natural Resources Conservation Service. Available online at http:// websoilsurvey.nrcs.usda.gov/. Accessed 5 February 2013.

45. Sorensen, L. H., Schneider, A. T., and Davis, J. R. 1991. Influence of sodium polygalacturonate sources and improved recovery of Verticillium spp. from soil. Phytopathology 81:1347 (Abstr.).

46. Stotzky, G., and Martin, R. T. 1963. Soil mineralogy in relation to the spread of Fusarium wilt of banana in Central America. Plant Soil 18:317-337.

47. Subramaniam, S., Maziah, M., Sariah, M., Puad, M. P., and Xavier, R. 2006 Bioassay method for testing Fusarium wilt disease tolerance in transgenic banana. Sci. Hortic. (Amsterdam) 108:378-389.

48. vanBruggen, A. H. C., and Grünwald, N. J. 1996. Tests for risk assessment of root infection by plant pathogens. Pages 293-310 in: Methods for Assessing Soil Quality. J. W. Doran and A. J. Jones, eds. Soil Sci. Soc. America Pub. \#49. Soil Science Society of America, Inc., Madison, WI.

49. Woltz, S. S., and Engelhard, A. W. 1973. Fusarium wilt of chrysanthemum effect of nitrogen source and lime on disease development. Phytopathology 63:155-157.

50. Woltz, S. S., and Jones, J. P. 1981. Micronutrient effects on the in vitro growth and pathogenicity of Fusarium oxysporum $\mathrm{f}$. sp. lycospersici. Phytopathology 58:336-338. 